\title{
A whole-body mathematical model of cholesterol metabolism and its age-associated dysregulation
}

Mark T Mc Auley ${ }^{1 *+}$, Darren J Wilkinson ${ }^{2+}$, Janette JL Jones ${ }^{3+}$ and Thomas BL Kirkwood ${ }^{1+}$

\begin{abstract}
Background: Global demographic changes have stimulated marked interest in the process of aging. There has been, and will continue to be, an unrelenting rise in the number of the oldest old ( $>85$ years of age). Together with an ageing population there comes an increase in the prevalence of age related disease. Of the diseases of ageing, cardiovascular disease (CVD) has by far the highest prevalence. It is regarded that a finely tuned lipid profile may help to prevent CVD as there is a long established relationship between alterations to lipid metabolism and CVD risk. In fact elevated plasma cholesterol, particularly Low Density Lipoprotein Cholesterol (LDL-C) has consistently stood out as a risk factor for having a cardiovascular event. Moreover it is widely acknowledged that LDL-C may rise with age in both sexes in a wide variety of groups. The aim of this work was to use a whole-body mathematical model to investigate why LDL-C rises with age, and to test the hypothesis that mechanistic changes to cholesterol absorption and LDL-C removal from the plasma are responsible for the rise. The whole-body mechanistic nature of the model differs from previous models of cholesterol metabolism which have either focused on intracellular cholesterol homeostasis or have concentrated on an isolated area of lipoprotein dynamics. The model integrates both current and previously published data relating to molecular biology, physiology, ageing and nutrition in an integrated fashion.
\end{abstract}

Results: The model was used to test the hypothesis that alterations to the rate of cholesterol absorption and changes to the rate of removal of LDL-C from the plasma are integral to understanding why LDL-C rises with age. The model demonstrates that increasing the rate of intestinal cholesterol absorption from $50 \%$ to $80 \%$ by age 65 years can result in an increase of LDL-C by as much as $34 \mathrm{mg} / \mathrm{dL}$ in a hypothetical male subject. The model also shows that decreasing the rate of hepatic clearance of LDL-C gradually to $50 \%$ by age 65 years can result in an increase of LDL-C by as much as $116 \mathrm{mg} / \mathrm{dL}$.

Conclusions: Our model clearly demonstrates that of the two putative mechanisms that have been implicated in the dysregulation of cholesterol metabolism with age, alterations to the removal rate of plasma LDL-C has the most significant impact on cholesterol metabolism and small changes to the number of hepatic LDL receptors can result in a significant rise in LDL-C. This first whole-body systems based model of cholesterol balance could potentially be used as a tool to further improve our understanding of whole-body cholesterol metabolism and its dysregulation with age. Furthermore, given further fine tuning the model may help to investigate potential dietary and lifestyle regimes that have the potential to mitigate the effects aging has on cholesterol metabolism.

\footnotetext{
* Correspondence: mcaulem@hope.ac.uk

'Equal contributors

${ }^{1}$ Campus for Ageing and Vitality, Newcastle University, Henry Wellcome Biogerontology Building, Newcastle upon Tyne NE4 5PL, United Kingdom Full list of author information is available at the end of the article
} 


\section{Background}

Lipid metabolism has a key role to play in human longevity and healthy ageing. This has been emphasized by recent genetic studies examining the lipoprotein phenotype in individuals with exceptional longevity $[1,2]$. It is highly probable such subjects with exceptional longevity and favourable lipoprotein profiles have avoided CVD. CVD is the primary cause of mortality in developed countries, with almost $40 \%$ of males and $30 \%$ of females in the United Kingdom over the age of 85 years living with the condition [3]. Of the components of lipid metabolism, elevated LDL-C has consistently stood out as a risk factor for CVD [4]. This cholesterol sub-fraction has been connected to atherosclerosis, a process regarded as the underlying pathogenesis for coronary heart disease (CHD) and stroke, the leading forms of CVD [5]. Studies have repeatedly demonstrated that regardless of physical activity levels and nutritional status, LDL-C has been shown to rise with age in both males and females in a diverse range of groups [6,7]. Understanding why LDL-C rises with age is complex; nevertheless rodent studies have indicated that increases in intestinal cholesterol absorption or possibly a decrease in the plasma clearance rate of LDL-C may have a mechanistic role to play [8-10]. In this paper we examine the hypothesis that these two mechanisms are central to understanding why LDL-C increases with age. To test this hypothesis a number of steps were required. Firstly, it was necessary to study both intestinal cholesterol absorption and LDL-C plasma clearance within an integrative framework which incorporated the other fundamental biological components of this complex system $[11,12]$. This required incorporating the interactions of the individual elements of this system. Secondly, it was important to investigate changes both to intestinal cholesterol absorption and LDL-C clearance over an extended period of time. Clearly it would have been difficult to test our hypothesis within this framework using conventional in vivo or in vitro techniques as such approaches can be resource intensive, expensive, time consuming, unpractical and potentially unethical [13]. Furthermore, whole-body cholesterol metabolism is a complex system with a variety of non-linear interactions among its various components, including both positive and negative feedback and complex crosstalk between elements such as cholesterol synthesis and absorption [14].

Utilizing a mechanistic mathematical model offered an alternative means of overcoming these difficulties and presented a cheap, ethical and practical way of investigating our hypothesis [13]. However, as existing computational models of cholesterol metabolism were either of an intracellular nature, lipoprotein kinetic focused, or compartmental in nature, they failed to incorporate the ageing process or address the holistic nature of our question and were thus determined to be unsuitable [15,16]. Consequently we constructed a whole-body mathematical model of cholesterol metabolism which was used to explore changes to both the rate of intestinal cholesterol absorption and the hepatic rate of clearance of LDL-C from the plasma. The model showed that of these two mechanisms, changes to the rate of LDL-C removal from the plasma with age had the most significant effect on cholesterol metabolism. The model was constructed using a series of coupled ordinary differential equations (ODEs). Additionally, the model was coded in the systems biology markup language (SBML) format and submitted to the Biomodels database to facilitate its updating and future exchange $[17,18]$. To build the model a wide variety of data was used including previously published data from a range of fields such as molecular biology, nutrition, physiology and biochemistry.

\section{Whole-body cholesterol metabolism}

Cholesterol has a vital role to play in the human body. It is a key constituent of all cell membranes being involved in membrane fluidity; it is the precursor of steroid hormones which control a range of physiological functions, and bile salts, which are necessary for the intestinal absorption of cholesterol, fats and lipid soluble vitamins $[19,20]$. The mechanisms underpinning cholesterol metabolism interact to preserve the balance of cholesterol in the body. This balance is maintained by coordinated interactions between cholesterol absorption, excretion and synthesis.

\section{Intake, absorption and excretion}

Cholesterol from both the diet and bile is taken up by the small intestine daily. Cholesterol absorption is an inefficient process and can vary significantly from person to person. The percentage of cholesterol absorbed in healthy subjects (both male and female) is in the range of $29-80 \%$ [21]. The heterogeneity in cholesterol absorption has been attributed to its complexity, which involves a large number of enzymes and transport proteins in a multi-step process, however the way these mechanisms interact to regulate absorption efficiency remains unknown [22]. It is clear that during digestion, bile acids are released from the liver and gall bladder into the intestine and as cholesterol is practically insoluble in aqueous environments, the bile acids serve to create lipid micelles [23]. The micelles are then transported to the brush border of jejunal enterocytes, where the cholesterol is transferred into the enterocytes. At this point the story becomes nebulous, as the mechanism(s) by which micellar cholesterol is absorbed through the brush border membranes independent of bile salt uptake 
remains a mystery. A long standing hypothesis suggests that cholesterol absorption occurs by passive diffusion down a concentration gradient [24,25]. However, recent evidence supports the hypothesis that protein facilitated mechanisms are involved in cholesterol uptake by the enterocyte [26,27]. When cholesterol is inside enterocytes, it has been suggested that it can be transported back to the intestinal lumen by a class of membrane proteins known as adenosine triphosphate binding cassette transporters. It has been proposed that these transporters may serve to efflux cholesterol from the enterocyte back into the intestinal lumen for excretion [28]. Although the precise mechanisms of cholesterol absorption are not yet fully understood, it is known that cholesterol not transported back to the intestinal lumen is esterified in the enterocyte by acyl-CoA-cholesterol acyltransferase (ACAT), assembled and packaged, together with triglycerides, into chylomicrons. Chylomicrons are just one of many lipid carriers, known as lipoproteins, found in the circulation of mammals. According to their density, lipoproteins are categorised as chylomicrons, very low density lipoproteins (VLDL), intermediate density lipoproteins (IDL), low density lipoproteins (LDL) and high density lipoproteins (HDL) [29]. Chylomicrons transport absorbed cholesterol via the lymph to the liver [30].

\section{The liver and whole-body cholesterol metabolism}

The liver is the central organ involved in cholesterol metabolism. It is actively involved in the uptake of cholesterol from lipoproteins, is an important site for de novo synthesis and is capable of storing cholesterol as esters after esterification by ACAT. Furthermore, it is involved in the secretion of cholesterol-containing lipoproteins and is the sole organ capable of removing excess cholesterol from the body, either by secretion into bile or by conversion into bile acids [31]. Bile acids are synthesised from cholesterol in the liver and facilitate the solubilisation of cholesterol, a prerequisite for cholesterol absorption. Bile acids are released postprandially and will not solubilise dietary lipids unless above a critical concentration. The concentration gradient is generated by two factors. Firstly, bile acids are powerful acids that are impermeable to cell membranes. Secondly, the majority of bile acids are reabsorbed from the small intestine and return to the liver via the portal vein, where they are taken up by hepatocytes and resecreted into bile [32]. The conservation of bile acids by active absorption from the small intestine results in a hepatic pool of bile acids that cycles several times with each meal. In humans, the bile acids circulate between six and 10 times per day, while around $400 \mathrm{mg}$ of bile acids is lost daily through faecal excretion. A decreased return of bile acids to the liver is compensated for by increased de novo synthesis from cholesterol in order to maintain the bile salt pool [33]. Cholesterol not converted to bile acids or secreted into bile can be released from the liver into the circulation and transported to peripheral tissue. The liver secretes VLDLs and on entering the circulation VLDLs are hydrolysed by lipoprotein lipase (LPL) [34], leading to the formation of VLDL remnants and IDLs. IDLs are either taken up by the liver or further hydrolysed to LDLs, which are the main cholesterol carrier in the blood [35]. LDL is taken up by the liver or by peripheral cells, either independently or via the LDL-receptor (LDLR). Expression is high in the liver but LDLRs are also expressed in peripheral tissue [36,37]. Hepatic LDLR (HLDLR) expression is transcriptionally regulated in response to intracellular cholesterol levels [38].

\section{Reverse cholesterol transport}

The flux of cholesterol from peripheral tissue to the liver is known as reverse cholesterol transport (RCT). This pathway plays a vital role in maintaining cholesterol balance, with its action resulting in the movement of cholesterol from peripheral tissue to the liver [39]. Consequently RCT presents the only route for excess cholesterol generated in peripheral tissue to be eliminated from the body. HDL plays a crucial part in RCT $[40,41]$. HDL synthesis takes place in the liver and intestine, commencing with the generation of nascent particles, small discoidal structures lacking cholesterol. HDL acquires free cholesterol from the cell membranes of several tissues, which is esterified by the action of lecithin:cholesterol acyltransferase (LCAT), resulting in cholesteryl ester-rich, mature HDL particles. The transport of high density lipoprotein cholesterol (HDL-C) to the liver may follow several routes. In the presence of the enzyme cholesteryl ester transport protein (CETP), a portion of cholesterol esters from the HDL particle can be redistributed to other lipoproteins (e.g. VLDL and LDL) in exchange for triglyceride [42]. This cholesterol is delivered back to the liver via the LDLR. An alternative route involves the mature $\mathrm{HDL}$ particle binding directly to scavenger receptors $\mathrm{BI}$ (SR-BI) on the liver [43].

\section{Cholesterol synthesis}

Almost all the tissues in the body are capable of synthesizing cholesterol from acetyl-Co enzyme A (CoA) in a series of enzyme-mediated steps that are mainly restricted to the endoplasmic reticulum (ER). The major rate-controlling enzyme in this pathway is 3-hydroxy-3-methylglutaryl CoA (HMG-CoA) reductase. Cholesterol homeostasis is regulated in two ways, firstly, when the content of unesterified cholesterol in cells increases, the expression of the LDLR protein decreases. Furthermore, two key enzymes 
involved in cholesterol synthesis are repressed, thus, any subsequent increase in cellular cholesterol diminishes. When cholesterol levels fall, these pathways are reactivated $[38,44,45]$.

\section{Dysregulation of cholesterol metabolism with age}

The interaction between cholesterol absorption, synthesis, and excretion maintains whole- body cholesterol metabolism. A change to any of them can significantly influence the others. For example, numerous studies have shown that inhibition of cholesterol synthesis results in increased intestinal cholesterol absorption $[46,47]$. The close interaction between absorption and synthesis in maintaining cholesterol balance is consolidated by studies, which have shown that interference with cholesterol absorption is associated with increased cholesterol synthesis [47]. Dysregulation of cholesterol metabolism can lead to high levels of LDL-C, while population studies have consistently demonstrated that LDL-C rises with age in both males and females [7]. The reason for an increase in LDL-C in so many individuals across both genders remains unknown. Furthermore, the intrinsic mechanisms that contribute to the rise in LDL$\mathrm{C}$ with age remain incomplete; however a picture is beginning to emerge of potential candidates. A significant finding was the discovery that there is a gradual reduction in the rate of clearance of LDL-C from the circulation with age [48-50]. Adding further to this is the evidence that the number of hepatic LDLRs (HLDLRs) diminish with age in certain species [10,50]. Additionally, it has been reported that there is an increase in intestinal cholesterol absorption efficiency with age in rats $[8,51]$. However, to date no single intrinsic mechanism or combination of intrinsic mechanisms has conclusively been attributed to the rise in LDL-C with age [9]. Consequently our whole-body mathematical model investigated the hypothesis that age-related changes to the rate of intestinal cholesterol absorption and the rate of removal of LDL-C from the plasma could be responsible for the rise in LDL-C with age in humans.

\section{Results}

\section{Results overview}

Using the values listed in tables one and two, a sensitivity analysis was conducted, followed by a number of simulations that examined the key questions associated with this research. The model was able to replicate many of the integral features of whole-body cholesterol balance and displays qualitative behaviour similar to that observed in experimental studies [52]. For example, plasma LDL-C levels rose in response to increases in the intake of dietary cholesterol, however this was somewhat more sensitive than that predicted by a meta-analysis of the experimental literature, as for every $100 \mathrm{mg} /$ day increase in dietary cholesterol there was $\mathrm{a} \approx 10 \mathrm{mg} / \mathrm{dL}$ increase in LDL-C (Figure 1). Changes to cholesterol absorption were also investigated and the model showed that for every $10 \%$ increment in the rate of cholesterol absorption, this resulted in a $12.5 \mathrm{mg} / \mathrm{dL}$ increase in LDL-C. Finally, the model was used to investigate the hypothesis that age related changes to cholesterol absorption/a decrease in the clearance of LDL-C from the circulation result in the rise of LDL-C with age. The model showed that of these two mechanisms, changes to the rate of removal of LDL-C from the circulation had the most significant impact on LDL-C levels with age.

\section{Predictive capability of the model}

The model demonstrated that increasing cholesterol absorption from $50 \%$ to $80 \%$ and running a simulation from age 20 years to age 65 years resulted in an increase of plasma LDL-C by as much as $34 \mathrm{mg} / \mathrm{dL}$ (Figure 2, graph A). However, reducing the number of hepatic LDL receptors had a profound impact on the system, as an increase of $116 \mathrm{mg} / \mathrm{dL}$ in LDL-C was witnessed by age 65 years in response to a reduction in the number of these receptors by $50 \%$ (Figure 2 graph B). These rises were compared to that found in population studies (Figure 2 graphs $\mathrm{C}$ and $\mathrm{D}$ ) with changes to the rate of clearance of LDL-C clearly having the more significant impact on LDL-C levels.

\section{Sensitivity analysis-cholesterol absorption}

The initial concentrations of the various species are summarised in Table 1 . Where quantitative data was available, these values reflected the numbers found in the literature. A sensitivity analysis of the model was also conducted as the parameter values differ considerably in terms of their magnitude (Table 2) and we wanted to establish how changes to these parameters would affect the concentrations of key species. Cholesterol absorption $\left(k_{6}\right)$ is an example of one of the key parameters that was altered. The initial value of this parameter was set so that $50 \%$ of cholesterol entering the small intestine would be absorbed. However, although cholesterol absorption is tightly regulated, it is a process that can vary significantly from one individual to the next [21]. This range was used to test the sensitivity of the model to changes in $k_{6}$. The impact variations in cholesterol absorption has on LDL-C levels in the model is shown in (Figure 3).

\section{Sensitivity analysis-dietary cholesterol}

A literature review using PubMed revealed the existence of almost 200 publications containing information relating to the response of plasma cholesterol to dietary cholesterol feeding. These investigations were performed 

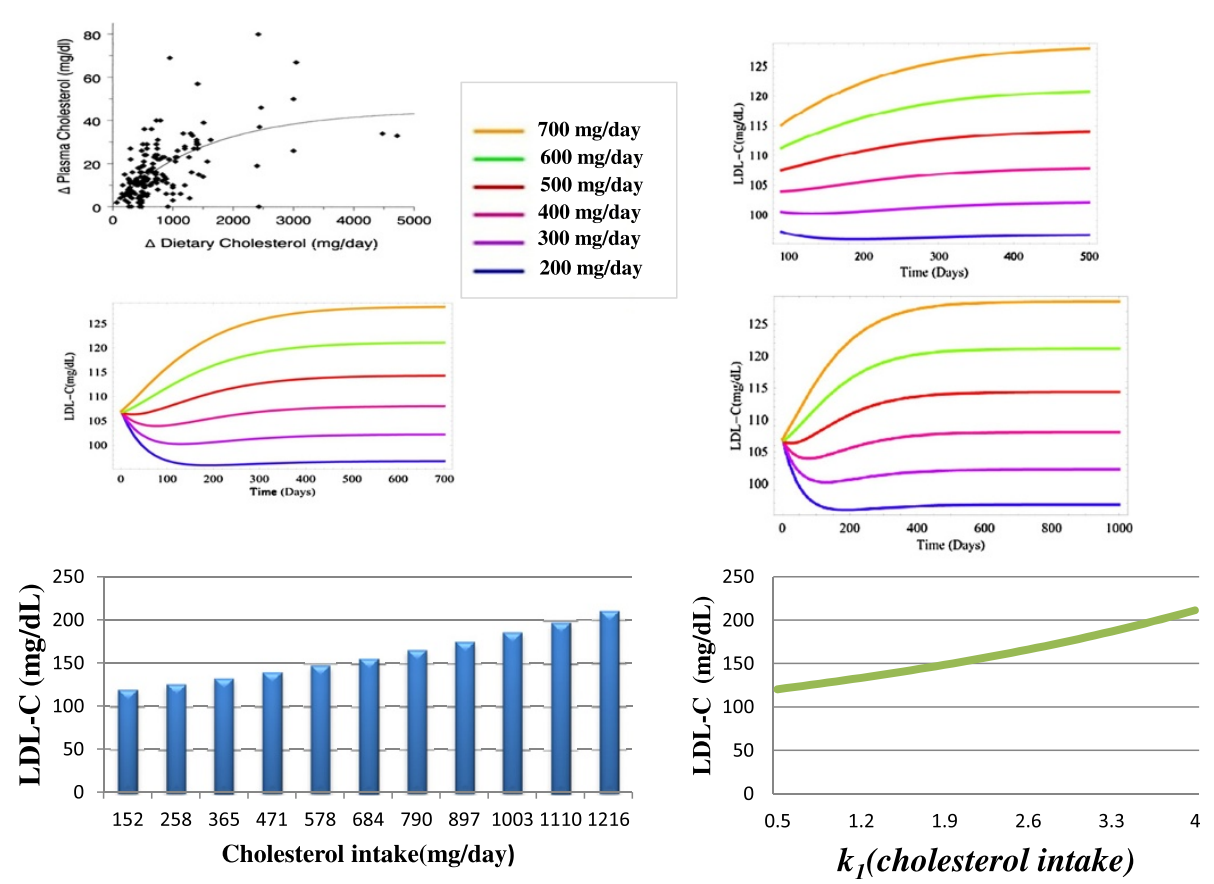

Figure 1 (A-F) The response of the model to changes in the intake of dietary cholesterol compared to a published meta-analysis. A) The relationship between mean change in dietary cholesterol (mg/day) and mean change in plasma cholesterol levels $(\mathrm{mg} / \mathrm{dL})$ in $167 \mathrm{cholesterol}$ feeding studies published between 1960 and 1999 (McNamara 2000). B-D) The response of the model to changes in dietary cholesterol over a range of time periods. E) Steady-state levels of LDL-C for various different intakes of dietary cholesterol. F) The change in LDL-C levels in response to various different values of the parameter $k_{1}$ (cholesterol ingestion). Results of both E\&F were generated from a sensitivity analysis of the model using the software tool Copasi.

in both young and old individuals. Importantly among these publications, a meta-analysis by McNamara (2000) revealed that in response to increased levels of dietary cholesterol, plasma cholesterol plateaus at high levels of cholesterol intake [52]. The meta-analysis by McNamara also reported that the total plasma cholesterol response to dietary cholesterol is $0.023 \mathrm{mg} / \mathrm{dL}$ per $\mathrm{mg} /$ day cholesterol increase (Figure 1, graph A). Of this, $0.019 \mathrm{mg} / \mathrm{dL}$ is in the LDL-C fraction. Therefore, for each $100 \mathrm{mg} /$ day increase in dietary cholesterol intake in the model, a $1.9 \mathrm{mg} / \mathrm{dL}$ increase in LDL-C was expected. Importantly, McNamara reported that this increase is independent of other types of lipid in the diet and the baseline plasma cholesterol level. Therefore, the model was exposed to a decrease of $200 \mathrm{mg} /$ day and increases of up to $700 \mathrm{mg} /$ day of dietary cholesterol (Figure 1, graphs $\mathrm{A}-\mathrm{C}$ ). $\mathrm{A} \approx 10 \mathrm{mg} / \mathrm{dL}$ increase in LDL-C was observed for every $100 \mathrm{mg}$ increase in dietary cholesterol which was $8 \mathrm{mg}$ greater than the value predicted in the meta-analysis by McNamara. We also conducted a sensitivity analysis of the parameter $k_{1}$ to highlight the different steady-state levels of LDL-C for various intakes of dietary cholesterol (Figure 1, graphs E\&F and Additional file 1). No increase in HDL-C was observed in response to changes in dietary cholesterol.

\section{Hypothesis testing- ageing and cholesterol absorption/ LDL-C plasma removal}

Aging results in a rise in LDL-C in both sexes (Figure 2, graphs $C$ and D) [7]. The reason(s) for an increase in LDL-C in so many individuals across both genders remains unknown and the issue is the subject of debate as nutritional status and physical activity levels may differ within the population sample. The intrinsic mechanism(s) that contribute to the rise in LDL-C with age remain incomplete; however a picture is beginning to emerge of potential candidates. As mentioned previously, rodent studies have shown that cholesterol absorption efficiency increases markedly with aging $[8,21]$. It was also mentioned that there is a gradual reduction in the rate of clearance of LDL-C from the circulation with age in rodents. Adding further to this is the evidence that the number of hepatic LDLRs diminish with age in certain species [29]. When cholesterol absorption 


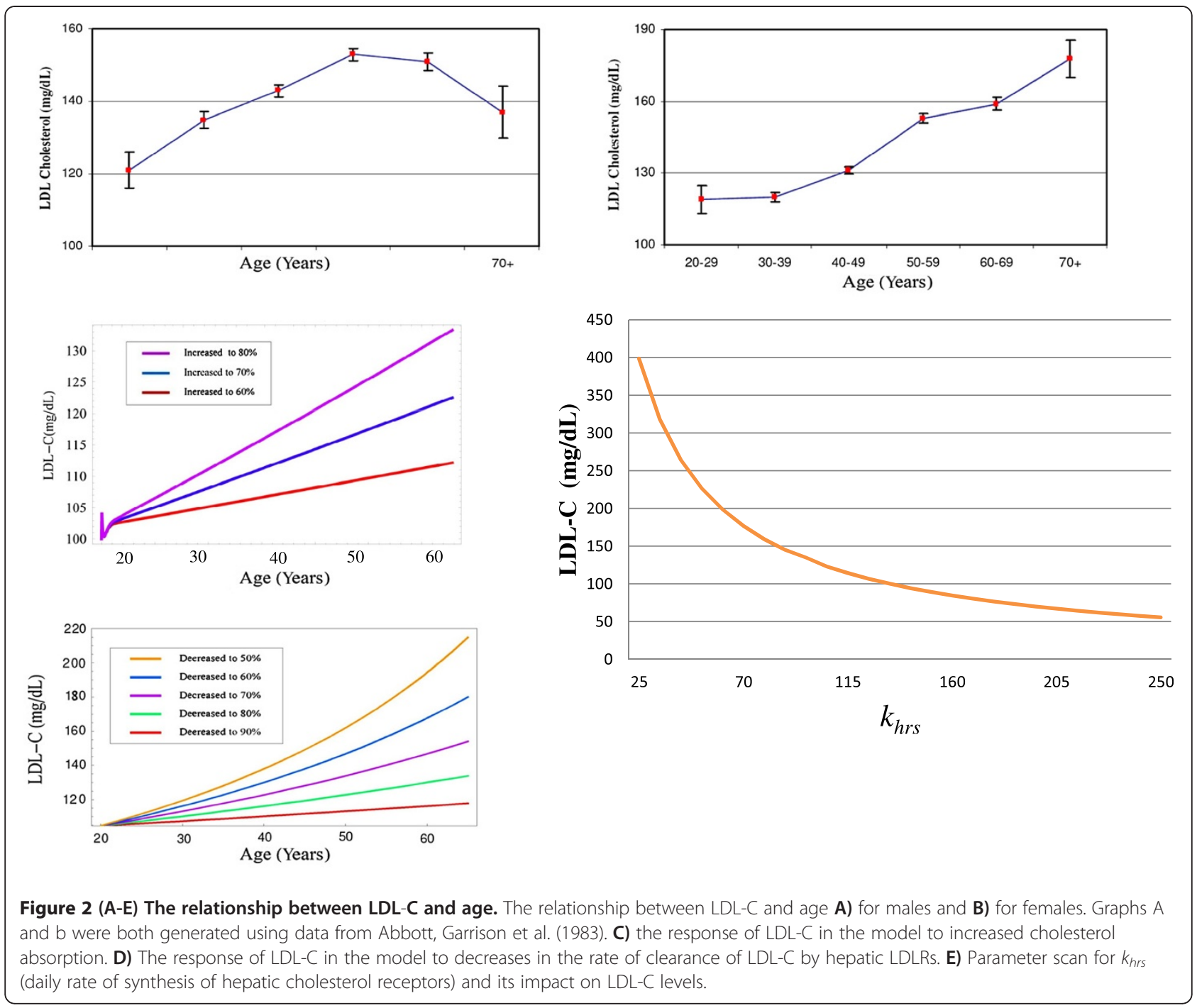

efficiency was increased in 10\% increments between $50 \%$ and $80 \%$ by age 65 years, 12,24 and $34 \mathrm{mg} / \mathrm{dL}$ increases respectively, in LDL-C were observed (Figure 2, graph A). Next, reducing the number of hepatic LDL receptors (HLDLRs) was investigated. The number of HLDLRs was reduced in the range $90-50$ by age 65 years. This was done by gradually decreasing the rate of synthesis $k_{h r s}$. This had a significant effect on the model as LDL-C raised by $116,76,49,26$ and $11 \mathrm{mg} / \mathrm{dL}$ respectively (Figure 2, graph B). A parameter scan of $k_{h r s}$ was also conducted (Figure 2, graph E).

\section{Discussion}

We have constructed a whole-body mathematical model of cholesterol metabolism using data from a wide variety of sources and integrated this data within a series of coupled ODEs. Previous computational models have focused on the intracellular regulation of cholesterol metabolism $[16,53]$ or have focused on the metabolic fate of a particular lipoprotein or their receptor mediated endocytosis $[54,55]$, while other mathematical models of lipid metabolism have centred on compartmental approaches, where by lipoproteins are represented by compartments [56]. Our model attempts to include all the major components of whole-body cholesterol balance and to our knowledge is the first model of its type built using such a framework. Our model provides an insight into the complex interplay of cholesterol metabolism with the aging process. The model has many areas that require further development, however, when the model progresses in the future it would be worthwhile to investigate how 
Table 1 List of species, their abbreviations and their initial values

\begin{tabular}{lll}
\hline Dietary Species & Symbol & Initial Value \\
\hline Dietary cholesterol & DC & $304 \mathrm{mg}$ \\
\hline Intestinal Species & & \\
\hline Intestinal cholesterol & IC & $3150 \mathrm{mg}$ \\
\hline Intestinal bile salts & IBS & $467 \mathrm{mg}$ \\
\hline Intestinal cholesterol synthesis & ICS & $\begin{array}{l}0 \text { (Source } \\
\text { Species) }\end{array}$ \\
\hline $\begin{array}{l}\text { Intestinal nascent high density } \\
\text { lipoprotein synthesis }\end{array}$ & INHDLS & $\begin{array}{l}\text { 0 (Source } \\
\text { species) }\end{array}$ \\
\hline
\end{tabular}

Excreted Species

\begin{tabular}{lll}
\hline Excreted cholesterol & EC & 0 \\
\hline Excreted bile salts & EBS & 0 \\
\hline
\end{tabular}

Hepatic Tissue Species

\begin{tabular}{|c|c|c|}
\hline Hepatic cholesterol synthesis & $\mathrm{HCS}$ & $\begin{array}{l}0 \text { (Source } \\
\text { Species) }\end{array}$ \\
\hline Hepatic nascent HDL synthesis & HNHDLS & $\begin{array}{l}0 \text { (Source } \\
\text { Species) }\end{array}$ \\
\hline Hepatic bile salt pool & HBS & $400 \mathrm{mg}$ \\
\hline Hepatic free cholesterol & HFC & $60000 \mathrm{mg}$ \\
\hline $\begin{array}{l}\text { Hepatic low density } \\
\text { lipoprotein receptors }\end{array}$ & HLDLRs & $\begin{array}{l}100 \text { (Theoretical } \\
\text { value to represent } \\
\text { the number of hepatic } \\
\text { LDL receptors) }\end{array}$ \\
\hline $\begin{array}{l}\text { Hepatic low density } \\
\text { lipoprotein receptor }\end{array}$ & HLDLRSS & $\begin{array}{l}600 \text { (Source } \\
\text { species) }\end{array}$ \\
\hline
\end{tabular}

synthesis

Hepatic LDL receptors HLDLRD 0 (Sink species)

degradation

\begin{tabular}{lll}
\hline Hepatic cholesterol esters & HCE & $10000 \mathrm{mg}$ \\
\hline Scavenger receptor & SRB1 & 100 (Theoretical \\
class B type 1 & value to \\
& represent \\
& concentration of \\
& SRB1 receptors) \\
\hline
\end{tabular}

\section{Peripheral Tissue Species}

\begin{tabular}{lll}
\hline $\begin{array}{l}\text { Peripheral low density } \\
\text { lipoprotein receptors }\end{array}$ & PLDLRs & $\begin{array}{l}100 \text { (Theoretical } \\
\text { value) }\end{array}$ \\
\hline $\begin{array}{l}\text { Peripheral low density } \\
\text { lipoprotein receptors } \\
\text { synthesis }\end{array}$ & PLDLRsS & $\begin{array}{l}575.16 \text { (Source } \\
\text { species) }\end{array}$ \\
\hline
\end{tabular}

synthesis

\begin{tabular}{|c|c|c|}
\hline $\begin{array}{l}\text { Peripheral low density } \\
\text { lipoprotein receptors } \\
\text { degradation }\end{array}$ & PLDLRD & 0 (Sink species) \\
\hline Peripheral free Cholesterol & PFC & $57516 \mathrm{mg}$ \\
\hline Peripheral cholesterol esters & PCE & $9363 \mathrm{mg}$ \\
\hline Peripheral steroid synthesis & PSS & 0 (Sink species) \\
\hline Peripheral cholesterol synthesis & PCS & O(Source species) \\
\hline \multicolumn{3}{|l|}{ Plasma Species } \\
\hline $\begin{array}{l}\text { Low density lipoprotein } \\
\text { cholesterol }\end{array}$ & LDLC & $100 \mathrm{mg} / \mathrm{dL}$ \\
\hline $\begin{array}{l}\text { High density lipoprotein } \\
\text { cholesterol }\end{array}$ & HDLC & $45 \mathrm{mg} / \mathrm{dL}$ \\
\hline
\end{tabular}

Table 1 List of species, their abbreviations and their initial values (Continued)

\begin{tabular}{lll}
\hline $\begin{array}{l}\text { Nascent high density } \\
\text { lipoprotein }\end{array}$ & NHDL & $\begin{array}{l}100 \text { (Theoretical } \\
\text { value to represent } \\
\text { the initial number } \\
\text { of Nascent HDL) }\end{array}$ \\
\hline $\begin{array}{l}\text { Very low density lipoprotein } \\
\text { cholesterol }\end{array}$ & VLDLC & 20 mg/dL \\
\hline $\begin{array}{l}\text { Intermediate density } \\
\text { lipoprotein } \\
\text { cholesterol }\end{array}$ & IDLC & 20 mg/dL \\
\hline $\begin{array}{l}\text { Cholesteryl ester transfer } \\
\text { protein }\end{array}$ & CETP & $\begin{array}{l}100 \text { (Fixed boundary } \\
\text { condition) }\end{array}$ \\
\hline $\begin{array}{l}\text { Lecithin:cholesterol } \\
\text { acyltransferase }\end{array}$ & LCAT & $\begin{array}{l}100 \text { (Fixed boundary } \\
\text { condition) }\end{array}$ \\
\hline $\begin{array}{l}\text { Hormone sensitive } \\
\text { Lipase }\end{array}$ & HSL & $\begin{array}{l}100 \text { (Fixed boundary } \\
\text { condition) }\end{array}$ \\
\hline Lipoprotein Lipase & LPL & $\begin{array}{l}100 \text { (Fixed } \\
\text { boundary } \\
\text { condition) }\end{array}$ \\
\hline Hepatic Tissue Species and Peripheral Tissue & \\
\hline Species & & \\
\hline $\begin{array}{l}\text { Cholesterol ester } \\
\text { hydrolase }\end{array}$ & CEH & $\begin{array}{l}100 \text { (Fixed } \\
\text { boundary } \\
\text { condition) }\end{array}$ \\
\hline acyl coenzyme A: cholesterol & ACAT & $\begin{array}{l}100 \text { (Fixed } \\
\text { boundary } \\
\text { acyltransferase }\end{array}$ \\
& & condition) \\
\hline
\end{tabular}

changes to different combinations of parameters affect the overall behaviour of the system, as the model indicates that the dysregulation of cholesterol metabolism with age may involve perturbations to several components of this system. In tandem with investigating changes to combinations of parameters, the model may also be used to investigate combination therapy that may help to mitigate the effects aging has on cholesterol metabolism. For example, it would be straightforward to include hypothetical interventions that investigate different dietary regimes and also include the effects of variations in physical activity. For example, based on available literature the simple assumption could be made that consuming $3 \mathrm{~g} /$ day of fibre reduces cholesterol absorption by $15 \%[57,58]$. Therefore, the parameters could be adjusted accordingly to reflect this. Similarly the effect of consuming plant sterols, which are known to reduce cholesterol absorption $[59,60]$ could easily be investigated, as consumption of 1.8 to $2.0 \mathrm{~g}$ /day of plant sterols has been shown to lower both total and LDL-C concentrations by $10 \%$ to $15 \%$, respectively in a variety of different population groups [61-63]. Thus, this could be investigated by making alterations to the rate of cholesterol absorption in the model. 
Table 2 Summary of the reactions and parameter values used in the model

\begin{tabular}{|c|c|c|c|}
\hline Reaction & Parameter & Value & Units \\
\hline Cholesterol intake & $k_{1}$ & 1 & mg/day \\
\hline Bile salt release & $k_{2}$ & 6 & mg/day \\
\hline Hepatic return of bile salts & $k_{3}$ & 4.29 & mg/day \\
\hline Bile salt excretion & $k_{4}$ & $8.56 \times 10^{-1}$ & mg/day \\
\hline Bile salt synthesis & $k_{5}$ & 2.66 & mg/day \\
\hline Cholesterol absorption & $k_{6}$ & $5.29 \times 10^{-4}$ & mg/day \\
\hline Cholesterol excretion & $k_{7}$ & $5.29 \times 10^{-4}$ & mg/day \\
\hline $\begin{array}{l}\text { Intestinal Nascent HDL } \\
\text { synthesis }\end{array}$ & $k_{8}$ & $5 \times 10^{-4}$ & mg/day \\
\hline $\begin{array}{l}\text { Hepatic cholesterol } \\
\text { storage }\end{array}$ & $k_{9}$ & 1 & mg/day \\
\hline $\begin{array}{l}\text { Release of stored Hepatic } \\
\text { cholesterol }\end{array}$ & $k_{10}$ & 5.998 & mg/day \\
\hline $\begin{array}{l}\text { Hepatic Nascent HDL } \\
\text { Synthesis }\end{array}$ & $k_{11}$ & $5 \times 10^{-2}$ & mg/day \\
\hline $\begin{array}{l}\text { VLDL cholesterol } \\
\text { formation }\end{array}$ & $k_{12}$ & $1.6 \times 10^{-2}$ & $\mathrm{mg} / \mathrm{dL} / \mathrm{day}$ \\
\hline $\begin{array}{l}\text { Synthesis of hepatic } \\
\text { LDL receptors }\end{array}$ & $k_{h r s}$ & 100 & number/day \\
\hline $\begin{array}{l}\text { Hepatic } L D L \text { receptors } \\
\text { degradation }\end{array}$ & $k_{13}$ & $1 \times 10^{-3}$ & number/day \\
\hline $\begin{array}{l}\text { VLDL cholesterol hepatic } \\
\text { reuptake }\end{array}$ & $k_{14}$ & $4.96 \times 10^{-3}$ & $\mathrm{mg} / \mathrm{dL} / \mathrm{day}$ \\
\hline IDL cholesterol formation & $k_{15}$ & $4.3 \times 10^{-1}$ & $\mathrm{mg} / \mathrm{dL} / \mathrm{day}$ \\
\hline $\begin{array}{l}\text { IDL cholesterol hepatic } \\
\text { reuptake }\end{array}$ & $k_{16}$ & $5.4 \times 10^{-2}$ & $\mathrm{mg} / \mathrm{dL} / \mathrm{day}$ \\
\hline LDL cholesterol formation & $k_{17}$ & $3.8 \times 10^{-1}$ & $\mathrm{mg} / \mathrm{dL} /$ day \\
\hline $\begin{array}{l}\text { Hepatic } L D L \text { receptors } \\
\text { uptake of } L D L \text {-cholesterol }\end{array}$ & $k_{18}$ & $6.80 \times 10^{-2}$ & $\mathrm{mg} / \mathrm{dL} / \mathrm{day}$ \\
\hline $\begin{array}{l}\text { Hepatic receptor independent } \\
\text { uptake of } L D L \text {-cholesterol }\end{array}$ & $k_{19}$ & $5.0 \times 10^{-3}$ & $\mathrm{mg} / \mathrm{dL} / \mathrm{day}$ \\
\hline $\begin{array}{l}\text { Peripheral } L D L \text { receptors } \\
\text { uptake of } L D L \text {-cholesterol }\end{array}$ & $k_{20}$ & $6.75 \times 10^{-3}$ & $\mathrm{mg} /$ day/day \\
\hline $\begin{array}{l}\text { Peripheral independent } \\
\text { uptake of } L D L \text {-cholesterol }\end{array}$ & $k_{21}$ & $5.0 \times 10^{-6}$ & $\mathrm{mg} / \mathrm{dL} / \mathrm{day}$ \\
\hline $\begin{array}{l}\text { Synthesis of peripheral } \\
\text { LDL receptors }\end{array}$ & $k_{\text {prs }}$ & 100 & number/day \\
\hline $\begin{array}{l}\text { Peripheral LDL receptors } \\
\text { degradation }\end{array}$ & $k_{22}$ & $1 \times 10^{-2}$ & number/day \\
\hline $\begin{array}{l}\text { Peripheral cholesterol } \\
\text { storage }\end{array}$ & $k_{23}$ & $1.75 \times 10^{-2}$ & mg/day \\
\hline $\begin{array}{l}\text { Release of stored peripheral } \\
\text { cholesterol }\end{array}$ & $k_{24}$ & $1.07 \times 10^{-1}$ & mg/day \\
\hline Peripheral steroid production & $k_{25}$ & $5 \times 10^{-4}$ & mg/day \\
\hline $\mathrm{HDL}$ cholesterol formation & $k_{26}$ & $1.5 \times 10^{-5}$ & $\mathrm{mg} / \mathrm{dL} /$ day \\
\hline $\begin{array}{l}\text { CETP mediated transfer of } \\
\text { cholesterol to VLDL from HDL }\end{array}$ & $k_{27}$ & $10 \times 10^{-3}$ & $\mathrm{mg} / \mathrm{dL} / \mathrm{day}$ \\
\hline $\begin{array}{l}\text { CETP mediated transfer of } \\
\text { cholesterol to } L D L \text { from } \mathrm{HDL}\end{array}$ & $k_{28}$ & $1 \times 10^{-3}$ & $\mathrm{mg} / \mathrm{dL} / \mathrm{day}$ \\
\hline $\begin{array}{l}\text { Reverse cholesterol } \\
\text { transport }\end{array}$ & $k_{29}$ & $5.0 \times 10^{-2}$ & $\mathrm{mg} / \mathrm{dL} / \mathrm{day}$ \\
\hline $\begin{array}{l}\text { Maximum rate of intestinal } \\
\text { cholesterol synthesis }\end{array}$ & $I C S_{\max }$ & $1 \times 10^{2}$ & mg/day \\
\hline
\end{tabular}

Table 2 Summary of the reactions and parameter values used in the model (Continued)

\begin{tabular}{llll}
\hline $\begin{array}{l}\text { Intestinal cholesterol } \\
\text { synthesis threshold }\end{array}$ & ICS & $3.120 \times 10^{2}$ & $\mathrm{mg} /$ day \\
\hline $\begin{array}{l}\text { Sensitivity of intestinal } \\
\text { cholesterol synthesis }\end{array}$ & $\mathrm{IS}$ & 5 & $\begin{array}{l}\text { Fitting } \\
\text { parameter }\end{array}$ \\
\hline $\begin{array}{l}\text { Maximum rate of biliary } \\
\text { cholesterol release }\end{array}$ & $\mathrm{BCR}_{\max }$ & $2 \times 10^{3}$ & $\mathrm{mg} /$ day \\
\hline $\begin{array}{l}\text { Biliary cholesterol release } \\
\text { threshold }\end{array}$ & $\mathrm{BCR}_{\mathrm{t}}$ & $5.55 \times 10^{4}$ & $\mathrm{mg} /$ day \\
\hline $\begin{array}{l}\text { Sensitivity of the feedback } \\
\text { equation for biliary cholesterol }\end{array}$ & $\mathrm{BS}$ & 5 & $\begin{array}{l}\text { Fitting } \\
\text { parameter }\end{array}$ \\
\hline $\begin{array}{l}\text { Maximum rate of hepatic } \\
\text { cholesterol synthesis }\end{array}$ & $\mathrm{HCS} \max$ & $5 \times 10^{2}$ & $\mathrm{mg} /$ day \\
\hline $\begin{array}{l}\text { Sensitivity of hepatic } \\
\text { cholesterol synthesis }\end{array}$ & $\mathrm{HS}$ & 5 & $\begin{array}{l}\text { Fitting } \\
\text { parameter }\end{array}$ \\
\hline $\begin{array}{l}\text { Hepatic cholesterol } \\
\text { synthesis threshold }\end{array}$ & $\mathrm{HCS}_{\mathrm{t}}$ & $9.39 \times 10^{4}$ & $\mathrm{mg} /$ day \\
\hline $\begin{array}{l}\text { Maximum rate of peripheral } \\
\text { cholesterol synthesis }\end{array}$ & $\mathrm{PCS}_{\max }$ & $5 \times 10^{2}$ & $\mathrm{mg} /$ day \\
$\begin{array}{l}\text { Peripheral cholesterol } \\
\text { synthesis threshold }\end{array}$ & $\mathrm{PPC}_{\mathrm{t}}$ & $8.0342 \times 10^{4}$ & $\mathrm{mg} /$ day \\
$\begin{array}{l}\text { Sensitivity of peripheral } \\
\text { cholesterol synthesis }\end{array}$ & $\mathrm{PCSS}$ & 5 & $\begin{array}{l}\text { Fitting } \\
\text { parameter }\end{array}$ \\
\hline
\end{tabular}

As mentioned previously the model is by no means the finished product and several assumptions were made during the building of the model, which were necessary as considerable uncertainty still surrounds cholesterol metabolism. For example, in the majority of cases the functional form that best describes a reaction remains unknown. We did however include a number of feedback and feed-forward equations to describe the behaviour of cholesterol and bile salt synthesis as these are known to be subject to this type of action. At steady state, parameter values attempted to reflect a generic normolipididemic 20 year old male. Although parameter values were chosen for the model from available published literature, the ranges of parameter values are quite broad; however, given the nature and diversity of the literature used this was unavoidable. On certain occasions, parameter values simply did not exist, therefore reasonable values were chosen based on the published literature. An area of the model that could be developed further in the future is the kinetic parameters of the various enzymes involved in a number of the reactions. Presently, most of these enzymes have arbitrary values of 100 assigned to them to indicate that they have 'normal' enzymatic activity. In the future it would be worthwhile to use a resource such as BRENDA to amend these enzymes to include $k_{\mathrm{m}}$ and $k_{\text {cat }}$ values [64]. Despite these limitations it is hoped that in the future the model will prove to be a useful 

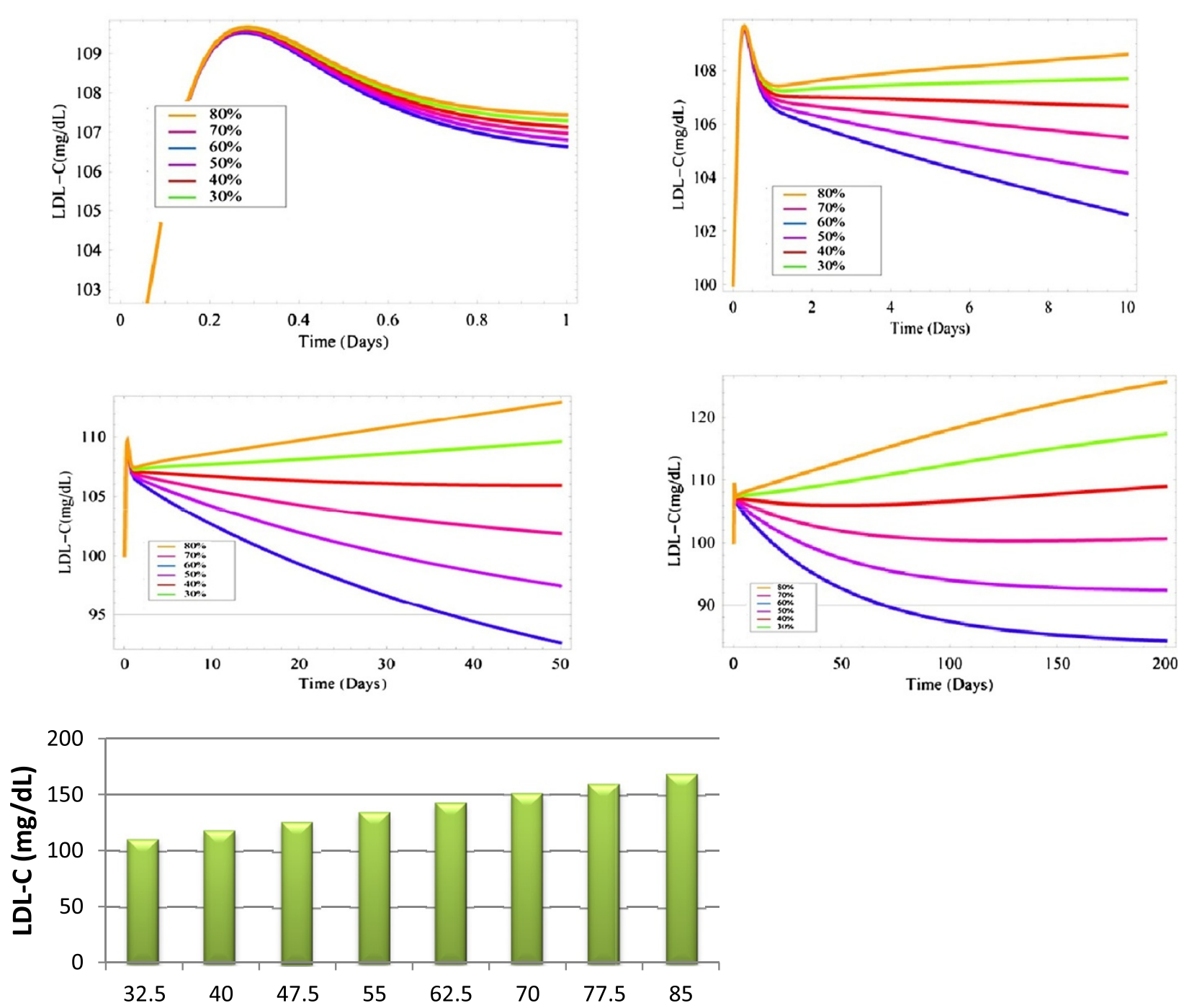

Cholesterol absorption $\left(k_{6}\right)$ as a percentage

Figure 3 (A-E) Changes to cholesterol absorption in the range 30-85\%. A-D) simulations of the model using MathSBML to show the response of $L D L-C$ to changes in the rate of efficiency of cholesterol absorption in the range $30-80 \%$ over a number of different time periods. E) Steady-state levels of LDL-C for various different percentages of cholesterol absorption. This was generated with the software tool Copasi.

tool for testing nutritional and lifestyle interventions that would be difficult, challenging or perhaps unethical to conduct using convention means.

Building the model has highlighted priorities for future experimental work, for example the need for experimentalists to work closely with computational modellers in order to generate appropriate quantitative data that is of benefit to systems biology models such as this one. Such data could be used to expand and enhance our model leading to a better understanding of cholesterol metabolism, particularly the interrelationship between cholesterol synthesis and absorption. This improved model could be used to gain additional insights into the factors associated with cholesterol metabolism that help to confer increased longevity and healthy aging. Appropriate dietary intervention strategies based on such models could be used to decrease the risk of CVD and prolong healthy aging. Models could be tailored for an individual's dietary, biochemical, genetic and social circumstances and as such models can be coded in SBML they would be relatively easy to extend, enhance and improve as more 
quantitative data becomes available. Furthermore, it would be worthwhile combining our model with existing models, such as that of atherosclerosis progression [65]. The portable nature of SBML also makes this a very realistic possibility, especially if models that are being merged have been designed using SBML [66,67]. Moreover, the model could be used to investigate crosstalk between cholesterol metabolism and fatty acid metabolism.

\section{Conclusions}

From the evidence presented in this paper it is clear that cholesterol metabolism is a complex multi-component system. Changes to this multi-component system as a result of the ageing process can lead to high levels of plasma cholesterol particularly LDL-C. There is an indisputable link between elevated levels of LDL-C and the risk of developing atherosclerosis, with population studies indicating that LDL-C rises with age in both sexes in a large number of individuals [5,68,69]. It is therefore unsurprising that recent genetic studies have associated lipid metabolism with longevity as it is apparent that maintaining cholesterol balance is vital to cardiovascular health $[1,2,70,71]$.

We developed a whole-body computational model to investigate the hypothesis that an increase in the rate of cholesterol absorption and a reduction in the rate of removal of LDL-C from the plasma were integral to understanding the dysregulation of cholesterol metabolism with age. We were of the opinion that existing models of cholesterol metabolism were limited and could not offer a sufficiently deep understanding of how an entire biological system changes with age, thus in this work a conscious effort was made to represent the interactions throughout the body. Results from the sensitivity analysis of the model indicated that the model requires further fine-tuning in the future before it could be used as a comprehensive tool for predicting changes to LDL-C in response to dietary cholesterol/ fats and intrinsic aging. None the less we used the model to investigate aging and it demonstrated that changes to the rate of removal of LDL-C to half its original value at age 65 years resulted in a $116 \mathrm{mg} / \mathrm{dL}$ rise in this cholesterol sub fraction, which is intimately connected with CVD. The model contrasts with other models of cholesterol metabolism in that it is implemented in a whole-body fashion and provides a template for building a quantitative systems level understanding of cholesterol metabolism and its interaction with aging. In the future the model could contribute to a better understanding of cholesterol metabolism so that the wider population could benefit in the same way as those individuals with exceptional longevity have from an altered lipid profile.

\section{Methods}

Deciding on model structure and the rationale for a whole-body approach

Historically, mathematical modelling has been used to investigate various aspects of both cholesterol and more generally lipid metabolism; however to our knowledge no model to date has been implemented to investigate cholesterol metabolism mechanistically within a wholebody framework, with the goal of understanding how intrinsic age-related biological changes affect this crucial biological system. In order to appreciate the rationale underpinning the whole-body approach that we adopted, it is worthwhile examining some of the models of cholesterol metabolism that have been developed previously. Additionally, it is worth exploring why these were unsuitable for this work. In general these models can be divided into three types; intracellular models of the cholesterol homeostasis genetic regulatory pathway; models of lipoprotein dynamics, and compartmental models. If we take the gene network approach, a recent version involved a boolean network model that assigned 33 different components of intracellular cholesterol homeostasis a boolean value. Simulations then led to the representation of intracellular cholesterol homeostasis as a boolean vector with each coordinate of the system denoting a biological species of the pathway [16]. It is easy to appreciate the utility of this approach as a means of better understanding the functioning of a gene regulatory network; however this strategy is not a mechanistic approach. It is primarily a state based representation of intracellular gene activity; therefore it is limited as it does not include the different biological compartments involved in cholesterol metabolism, such as absorption, and hepatic/peripheral cholesterol synthesis. Nor does it account for the synthesis of the various lipoproteins such as VLDL, IDL, LDL and their subsequent interactions with one another and with receptors both hepatically and peripherally. Finally, and significantly for this work it is difficult to imagine such models being able to test a biological hypothesis that centres on three factors, the aging process, cholesterol absorption and the removal of LDL-C from the plasma.

If mathematical models focused on lipoprotein kinetics are examined; one discovers a wide variety of models that have represented varying degrees of cholesterol metabolism and have centred to a large extent on the dynamics of the LDL receptor. Examples of such models go back as far as the early 1980s when Goldstein et al. presented a theoretical study of the interaction of LDL receptors with coated pits [72,73]. These were followed by other models of the same process [73] or more recent slight adaptations of this process [74]. These models have been beneficial from the point of view of elucidating the underlying dynamics which describe the 
interaction of LDL with its receptor and the associated underlying kinetics of this process. However, as with the intracellular models, these models focus on one particular, isolated aspect of cholesterol metabolism and do not portray the entire picture which is that cholesterol metabolism involves the coordinated action of several different biological systems operating in unison throughout the entire body.

The final approach that will be discussed is the compartmental methodology. Compartmental models, as the name suggests, contain a number of compartments, each containing a well mixed material. Each compartment has a number of connections leading into it and out of it. Biological material can flow from one compartment to another, and it can be added from the outside through a source, or it can be removed through a sink. Such systems exchange material with each other following certain rules [75]. These models have advantages such as being able to examine in some detail the interaction of lipoproteins and their derivatives. The major limitation of these models is that they are not based on underlying biological mechanisms; rather exchange rates are based on experimental inferences. Therefore, as with the previous approaches this method is also unsuitable for representing a mechanistic whole-body of cholesterol metabolism.

In order to overcome the limitations of the approaches that have been discussed, it was decided to represent cholesterol metabolism with the aid of biological

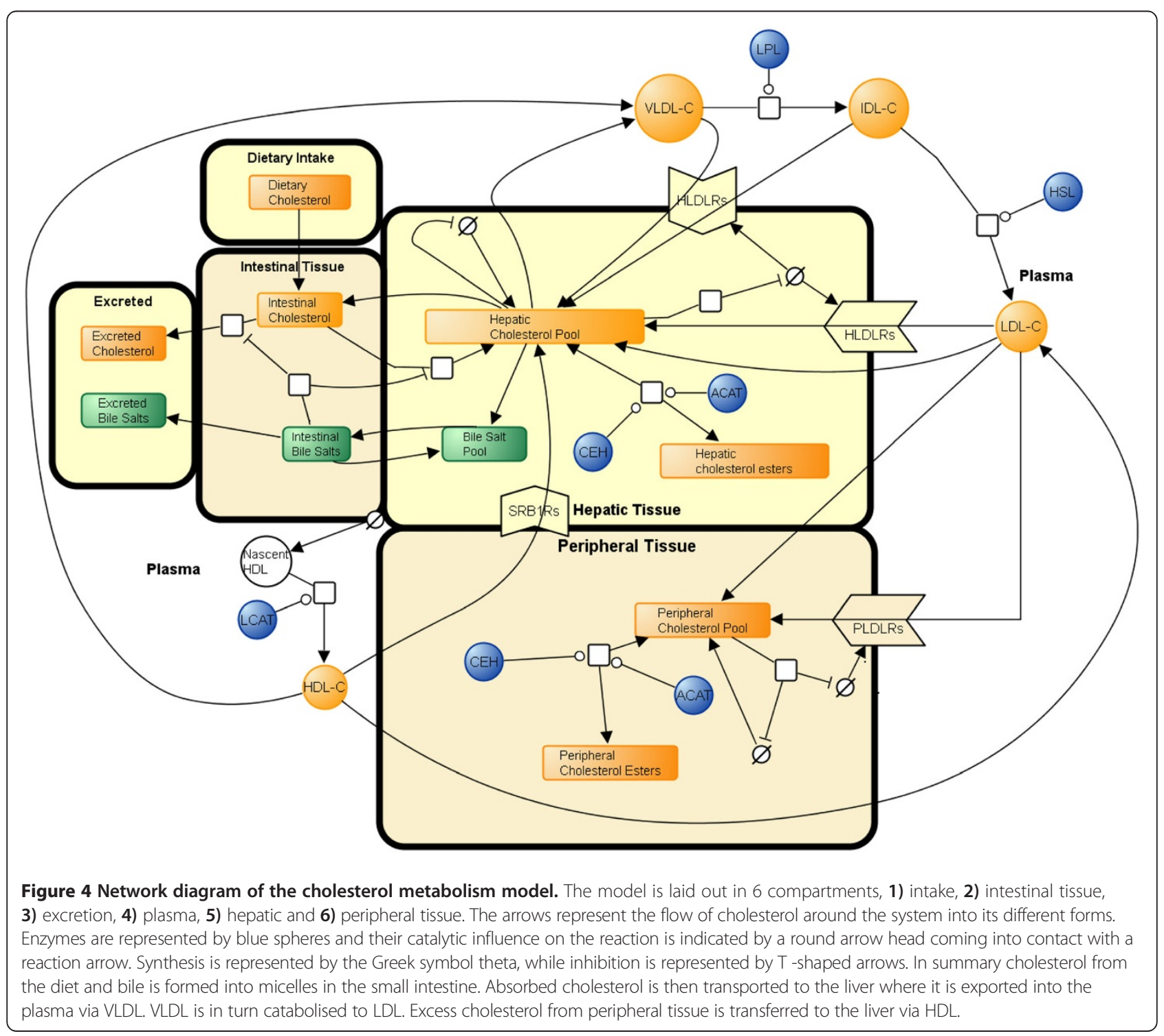


compartments that represented their real-world biological counterparts. The compartments contained quantitative details of the different forms of cholesterol. These forms are present in very high numbers (e.g. intestinal, hepatic and peripheral cholesterol is present in grams). This means that a stochastic approach would not offer significant benefits, as the intrinsic stochasticity in the system is negligible, and so a deterministic model was considered more appropriate to represent these species and their interactions. In order to implement this deterministic solution, we created a series of ordinary differential equations that were coupled and numerically integrated. This type of approach has previously been shown to be eminently suitable both for representing mechanistic biological reactions and for dealing with the time dimension associated with modelling the aging process [13]. In order to build the ODEs, we first needed to concisely represent the compartments and the fundamental components of whole-body cholesterol metabolism diagrammatically.

\section{Construction of a network diagram}

Whole-body cholesterol metabolism is a difficult process to reason about directly; therefore the first step in constructing a model of this nature was to assemble a network diagram (Figure 4) using Systems Biology Graphical Notation (SBGN). SBGN is a standardized means of graphical representation of biological systems that facilitated the drafting of a network diagram of cholesterol metabolism in a clear and unambiguous fashion [76]. This network diagram explicitly outlines each of the compartments and the biological species involved in whole-body cholesterol metabolism which we have discussed. Each of the components of Figure 4 was then abbreviated and used to construct a series of ODEs (Table 1 contains a summary of these abbreviations).

\section{Model assembly \\ Rationale for reaction forms}

The assumption was made that a large number of the reactions are of a first-order nature, where the rate of the reaction is directly proportional to the concentration of one of the reactants. This assumption was made to facilitate the evaluation of the model based on steady states and to allow for the determination of parameters when the model was compared to experimental data, moreover the reaction form that best describes a large number of these remains unknown. ODEs were constructed in an incremental fashion to meet certain steady states, eventually giving rise to a unified series of coupled ODEs and ultimately a whole-body mathematical model representing a generic twenty year old male. The model was built using MathSBML [77]. MathSBML is a software package that has been designed to work with Mathematica (version 5.2) [78], a pre-existing commercial software package developed to perform numeric, algebraic, graphical and many other tasks. In addition the software tool Copasi was used to perform some of the parameter scans and steady state examinations of the model [79]. The next section outlines the assembly of the ODEs and the biological functions that lie at their core. Additionally, the reasoning for the inclusion of each of the species in Figure 4 will be detailed along with the quantitative data that was used to make inferences about each of the steady states that these species gave rise to.

\section{Cholesterol intake}

As whole-body cholesterol metabolism was being dealt with, it was important first to include the dietary intake of cholesterol. According to Henderson et al. the average amount of cholesterol ingested daily in the UK by a male is $304 \mathrm{mg} /$ day [80]. Cholesterol intake was assigned the rate $k_{1}$ and set at an initial value of 1 . While dietary cholesterol $[\mathrm{DC}]$ had its initial condition set to a fixed value of 304 .

\section{Cholesterol synthesis}

Dietary cholesterol joins synthesised intestinal cholesterol. Additionally, cholesterol is also synthesised throughout the body [81]. To determine the daily rates of synthesis in each compartment, whole-body cholesterol synthesis was first calculated. According to Dietschy et al. humans synthesise $\approx 10 \mathrm{mg} / \mathrm{kg}$ of cholesterol daily, therefore a $70 \mathrm{~kg}$ man synthesises $\approx 700 \mathrm{mg} /$ day [81]. The amount of cholesterol synthesis that can be attributed to the liver, intestine and remaining peripheral tissue is uncertain [81]. Therefore, whole-body synthesis of cholesterol for a $70 \mathrm{~kg}$ man was based on the assumption that $\approx 70 \%$ of cholesterol synthesis takes place in the peripheral tissue and that $10 \%$ of this occurs in the intestine [82] (Table 3). This data was then used to make inferences about inter-compartmental cholesterol synthesis and functional relationships were derived to describe cholesterol synthesis in each compartment. Firstly, intestinal cholesterol synthesis was represented

Table 3 Breakdown of whole-body cholesterol synthesis

\begin{tabular}{ll}
\hline Compartment & Cholesterol synthesised \\
\hline Whole-Body (70 kg man) & $700 \mathrm{mg} /$ day \\
\hline Peripheral Tissue & $441 \mathrm{mg} /$ day $(70 \%$ of whole-body) \\
\hline Intestine & $49 \mathrm{mg} /$ day(10\% of peripheral) \\
\hline Liver & $210 \mathrm{mg} /$ day \\
\hline
\end{tabular}


with a negative feedback function (equation 1) were ICSmax represents the maximum amount of cholesterol that can be synthesised by the intestine in a day, IC represents intestinal cholesterol. $\mathrm{IC}_{\mathrm{t}}$ represents the intestinal cholesterol synthesis threshold and IS is a fitting parameter that represents the sensitivity of the negative feedback. It was assumed that the maximum rate of intestinal cholesterol synthesis would be $100 \mathrm{mg} /$ day (Figure 5, graph A).

$$
\text { Intestinal cholesterol Synthesis }=\frac{I C S_{\max }}{1+\left(I C / I C_{t}\right)^{I S}}
$$

We also derived similar functions for both hepatic and peripheral synthesis (equations $2 \& 3$, respectively). $\mathrm{HCS}_{\max }$ and $\mathrm{PCS}_{\max }$ represent the maximum amount of cholesterol that can be synthesised daily in the hepatic and peripheral compartments respectively. $\mathrm{HCS}_{\mathrm{t}}$ and $\mathrm{PPC}_{\mathrm{t}}$ represent hepatic and peripheral daily rates of synthesis thresholds respectively and HS and PCSS are fitting parameters that represent the sensitivity of the feedback in the two respective compartments. Based on experimental data it was assumed that the maximum daily rate of cholesterol synthesis in the liver would be $500 \mathrm{mg} /$ day, while the maximum rate of peripheral cholesterol synthesis was also estimated to be $500 \mathrm{mg} /$ day (Figure 5, graphs B and C).

$$
\text { Hepatic cholesterol synthesis }=\frac{H C S_{\max }}{1+\left(H F C / H C S_{t}\right)^{H S}}
$$

$$
\text { Peripheral cholesterol synthesis }=\frac{P C S_{\max }}{1+\left(P F C / P P C_{t}\right)^{P C S S}}
$$
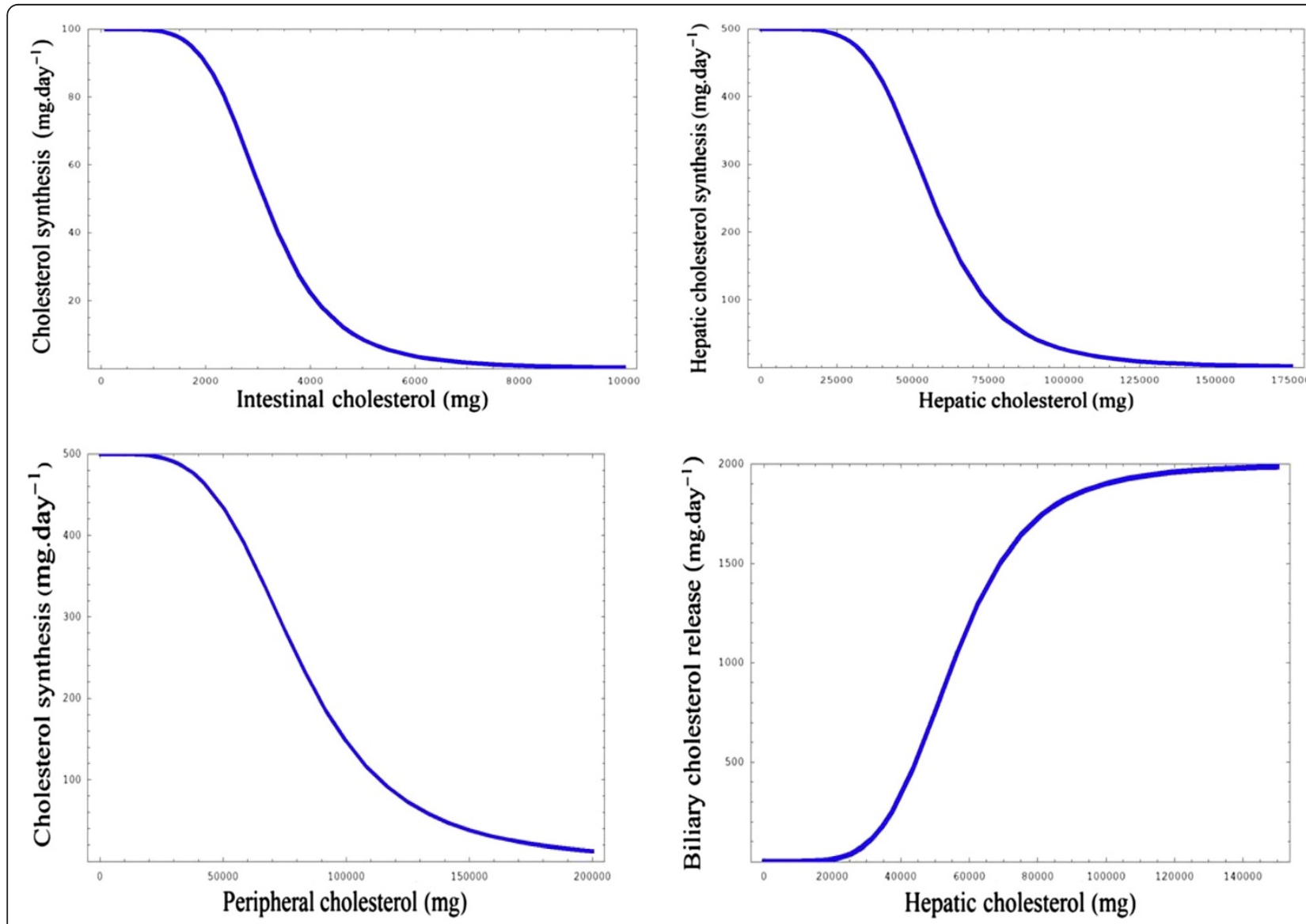

Figure 5 (A-D) Functions and simulations associated with model building. A) Graph of concentration of intestinal cholesterol versus cholesterol synthesis. C and D) Graphs of the functions for hepatic and peripheral cholesterol synthesis respectively. D) Graph of concentration of hepatic cholesterol versus biliary cholesterol release state values being reached for IDL-C and VLDL-C, respectively. 


\section{Hepatic biliary cholesterol release}

According to Grundy and Metzger dietary cholesterol also mixes intestinally with $\approx 1200 \mathrm{mg} /$ day of biliary cholesterol [83]. Therefore, a functional relationship was derived to describe the release of biliary cholesterol. This was done using a feed-forward equation (equation 2) as by nature this biological interaction is feed-forward. $\mathrm{BCR}_{\max }$ represents the maximum daily release of biliary cholesterol. $\mathrm{BCR}_{\mathrm{t}}$ represents the threshold of release of biliary cholesterol and HFC represents the hepatic pool of free cholesterol. Based on experimental data it was assumed that the maximum rate of release of biliary cholesterol would be $2000 \mathrm{mg} /$ day (Figure 5, graph D) [83].

$$
\text { Release of biliary cholesterol }=\frac{B C R_{\max }}{1+\left(B C R_{t} / H F C\right)^{B S}}
$$

\section{Estimating the steady-state levels of cholesterol in each compartment}

It was necessary to estimate the steady-state level of cholesterol in each compartment. According to Soars et al. in mammals this usually falls within the range of $100-200 \mathrm{mg} / 100 \mathrm{~g}$ of intestine. Also according to Soras et al. humans contain $30 \mathrm{~g}$ of intestine per $\mathrm{kg}$ of body weight [84]. The concentration of cholesterol in the intestine was determined based on several assumptions; firstly it was assumed that there is $150 \mathrm{mg}$ of cholesterol/100 $\mathrm{g}$ of intestine and secondly the assumption was made that the hypothetical individual weighed $\approx 70 \mathrm{~kg}$. Details of this calculation are provided in Table 4.

\section{Bile salts- hepatic synthesis and enterohepatic circulation}

Bile salts are synthesised from the hepatic pool of free cholesterol [HFC] at a rate of $\approx 400 \mathrm{mg} /$ day, while the hepatic bile salt pool [HBS] contains bile salt in the region of $\approx 4000 \mathrm{mg}$. This pool is released on average four to six times per day into the small intestine. Thus, a total of $\approx 24000 \mathrm{mg}$ of bile salts enter the small

Table 4 Calculating the steady-state level of intestinal cholesterol

\begin{tabular}{ll}
\hline The steady-state level of intestinal cholesterol \\
\hline Weight of intestine & $70^{* 30=2100 \mathrm{~g}}$ \\
\hline Number of $100 \mathrm{~g}$ segments in intestine & $2100 / 100=21$ \\
\hline Total amount of cholesterol & $21^{* 150 \mathrm{mg}}$ \\
equals the number of & \\
\hline $100 \mathrm{~g}$ segments times $150 \mathrm{mg}$ & $3150 \mathrm{mg}$ \\
\hline Total
\end{tabular}

intestine daily. The synthesis of bile salts is subject to negative feedback as the bile salt pool increases. Based on this information a reciprocal type function was derived to represent the production of bile salts (equation 5). Where $k_{5}$ is the rate constant for the hepatic production of bile salts.

$$
\text { Hepatic Production of Bile Salts }=\frac{k_{5}[H F C]}{[H B S]}
$$

Almost all bile salts are reabsorbed $(\approx 23600 \mathrm{mg} /$ day $)$ and return to the liver, while the remainder $(\approx 400 \mathrm{mg}$ / day) are excreted [85]. Bile salt release was assigned the rate constant $k_{2}$, while the hepatic return of bile salts was assigned the rate constant $k_{3}$. This rate was dependent on the concentration of intestinal bile salts [IBS] and the concentration of [IC]. The excretion of bile salts [EBS] was assigned the rate constant $k_{4}$. Putting this information together, ODEs 1 and 2 were assembled to describe how hepatic and intestinal bile salts change with time.

$$
\begin{aligned}
& \frac{d[H B S]}{d t}=\left(\frac{k_{5}[H F C]}{[H B S]}\right)+k_{3}[I B S][I C] \\
&-k_{2}[H B S](\mathrm{ODE} 1) \\
& \frac{d[I B S]}{d t}=k_{2}[B S P]-k_{3}[I B S][I C]-k_{4}[I B S](\mathrm{ODE} 2)
\end{aligned}
$$

\section{Cholesterol absorption and excretion}

The rate of cholesterol absorption and excretion depend on the concentration of intestinal bile salts. Over the years there has been controversy as to whether there is a difference between the absorption of dietary cholesterol and endogenously derived cholesterol. It is now accepted that they form an indistinguishable intestinal pool [54]. An assumption was made based on experimental data that $50 \%$ of cholesterol in the small intestine whether it

Table 5 Flux of cholesterol into and out of the small intestine on a daily basis

\begin{tabular}{ll}
\hline Contribution & Amount in $\mathbf{~ g / d a y}$ \\
\hline Diet & 304 \\
\hline Biliary cholesterol & 1200 \\
\hline Intestinal synthesis & 49 \\
\hline Total & 1553 \\
\hline Absorbed & $\approx 776.5$ \\
\hline Excreted & $\approx 776.5$ \\
\hline
\end{tabular}


originates from de novo synthesis, diet or bile will be absorbed in a normal individual each day while 50\% would be excreted $[21,86]$. Table 5 presents a summary of the estimated flux of cholesterol into and out of the small intestine on a day to day basis. The daily rates of cholesterol absorption and excretion were represented by the rate constants $k_{6}$ and $k_{7}$ respectively, and thus we were able to derive ODEs 3 and 4 that represent the change with time of $[I C]$ and excreted cholesterol $[E C]$, respectively.

$$
\begin{aligned}
\frac{d[I C]}{d t}= & k_{1}[D C]+\left(\frac{B C R_{\max }}{1+\left(B C R_{t} / H F C\right)^{B S}}\right) \\
& -k_{6}[I B S][I C]-k_{7}[I B S][I C] \\
& +\left(\frac{I C S_{\max }}{1+\left(I C / I C_{t}\right)^{I S}}\right) \quad(\mathrm{ODE} 3)
\end{aligned}
$$

$$
\frac{d[E C]}{d t}=+k_{7}[I B S][I C] \quad(\mathrm{ODE} 4)
$$

\section{Simulations of the mini model}

At this stage it was critical to create a mini-model, as determination of parameter values becomes increasingly complicated as models gain in size and complexity. The parameters for the mini model were determined using the baseline data outlined and the ODEs were numerically solved using MathSBML. Figure 6, graph A, shows the amount of cholesterol and bile salts excreted over a 100 day period. This output from the mini-system confirmed that the intestinal and intake compartments, and part of the hepatic compartment were behaving in a biologically realistic manner, thus further compartments and species were added to the system. It is important to note that the hepatic pool of cholesterol was fixed at a value of 100 during these simulations to facilitate parameterisation.
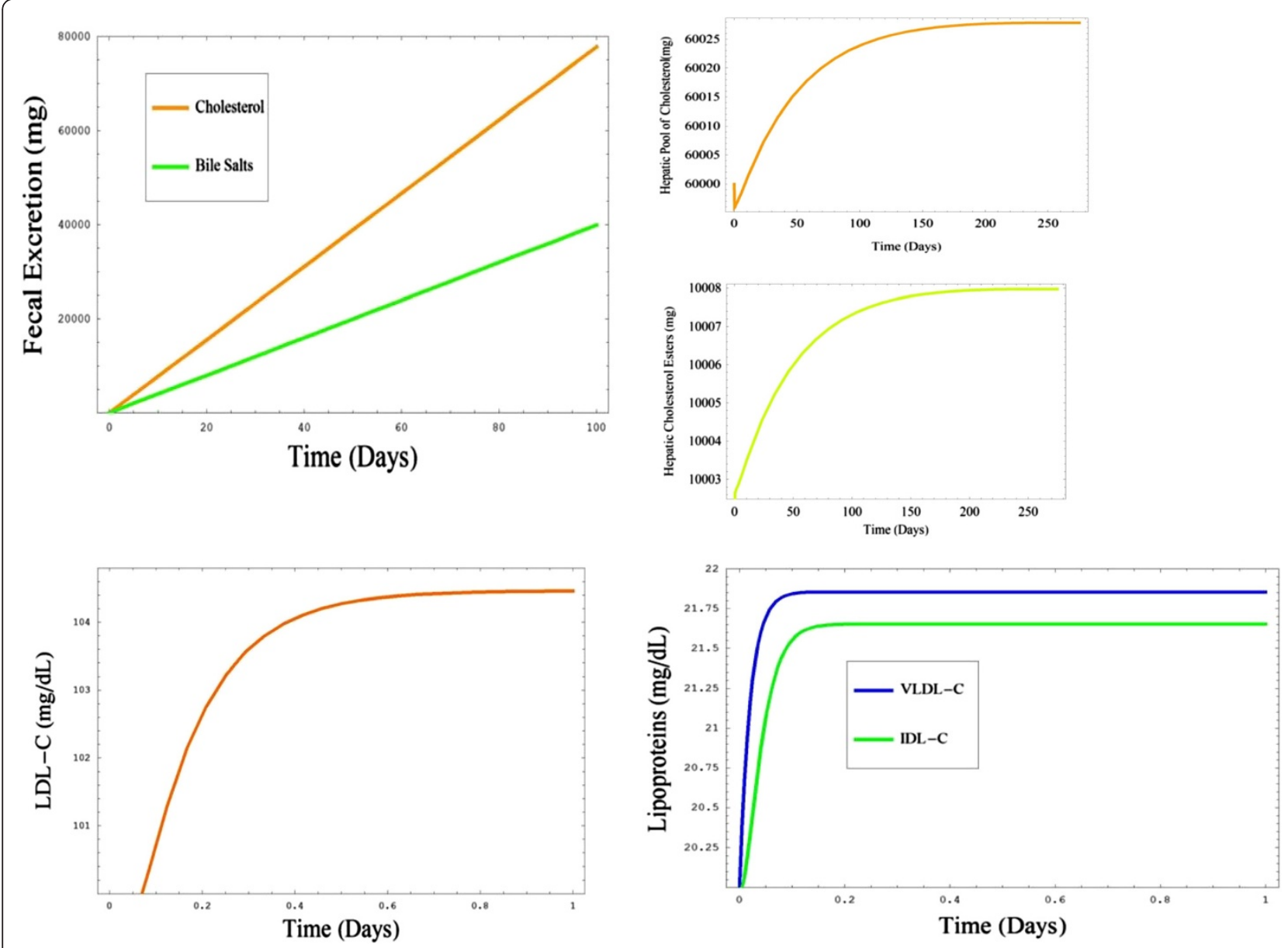

Figure 6 (A-E) Outputs and steady states associated with model building. A) Graph of the output from a simulation of the mini model that was constructed initially. It shows the faecal excretion of both cholesterol and bile salts over a 100 day period. B and C) Graphs showing the steady state values being reached for both the hepatic cholesterol pool and hepatic cholesterol esters respectively. D and E) Graphs showing steady state levels of LDL-C, IDL-C and VLDL-C. 
Table 6 Outlining how the concentration of cholesterol in the liver was determined (Non obese subjects ( $\mathrm{n}=19$ ))

\begin{tabular}{llll}
\hline Liver sample & Liver homogenate & Liver microsomes & Total \\
\hline Mean free cholesterol & $42.4 \mathrm{nmol} / \mathrm{mg}$ & $24.7 \mathrm{nmol} / \mathrm{mg}$ & $67.1 \mathrm{nmol} / \mathrm{mg}$ \\
\hline Mean esterified cholesterol & $9.9 \mathrm{nmol} / \mathrm{mg}$ & $8.6 \mathrm{nmol} / \mathrm{mg}$ & $18.5 \mathrm{nmol} / \mathrm{mg}$ \\
\hline & & Total Hepatic Cholesterol & $115.6 \mathrm{nmol} / \mathrm{mg}$ \\
\hline Molecular weight of cholesterol & 386.66 & Used to convert nmol to milligrams & \\
\hline$\therefore$ & Total cholesterol & $44.6979 \mu \mathrm{gg} / \mathrm{mg}$ or $0.0446979 \mathrm{mg} / \mathrm{mg}$ \\
\hline & Total esters & $7.1539 \mu \mathrm{gg} / \mathrm{mg}$ or $0.0071532 \mathrm{mg} / \mathrm{mg}$ \\
\hline \multirow{2}{*}{$\begin{array}{l}\text { Size of Human Liver }=1.5 \mathrm{~kg}[89] \\
\end{array}$} & Total free cholesterol & $37.5447 \mu \mathrm{mg} / \mathrm{mg}$ or $0.0375447 \mathrm{mg} / \mathrm{mg}$ \\
\cline { 2 - 3 } & $1.5 \mathrm{~kg}=1500000 \mathrm{mg}$ & \\
\cline { 2 - 3 } & $0.0446979 * 1500000=67046.85 \mathrm{mg}$ total cholesterol & \\
\cline { 2 - 3 } & $0.0071532 * 1500000=10792.80 \mathrm{mg}$ of cholesterol esters & \\
\hline
\end{tabular}

\section{Expansion of the mini model- further additions to the hepatic compartment}

It was now necessary to estimate the steady state level of hepatic cholesterol. The amount of cholesterol in the liver was determined using data from Sahlin et al., the molecular weight of cholesterol and the weight of an average human liver [87]. Calculations are outlined in Table 6. According to Cook humans weighing $\approx 70 \mathrm{~kg}$ contain $\approx$ $140 \mathrm{~g}$ of cholesterol [88]. Based on the calculations in Table 6 the assumption was made that half the cholesterol in man resides in the liver, while the remainder resides in peripheral tissue. The assumption was also made that $10 \mathrm{~g}$ of cholesterol is stored as esters in each compartment. The hepatic synthesis of cholesterol was previously estimated to be $210 \mathrm{mg} /$ day. When the hepatic pool of cholesterol increases, there is a rise in the conversion of cholesterol to esterified cholesterol. This reaction is catalysed by ACAT and the forward reaction was assigned the rate constant $k_{9}$. The reverse reaction is catalysed by cholesterol ester hydrolases $(\mathrm{CEH})$ and was assigned the rate constant $k_{10}$. Both ACAT and $\mathrm{CEH}$ were given fixed vales of 100 to represent 'normal' enzymatic activity. Thus, based on this information we were able to derive ODEs 5 and 6 to describe the change in both the [HFC] and hepatic cholesterol esters [HCE] with time.

$$
\begin{aligned}
& \frac{d[H F C]}{d t}= k_{19}+\left(k_{10}[H C E][C E H]\right) \\
&-\left(\frac{B C R_{\max }}{1+\left(B C R_{t} / H F C\right)^{B S}}\right) \\
&-k_{12}[H F C]-\left(\frac{k_{5}[H F C]}{[B S P]}\right)-k_{9}[H A C A T][H F C](\mathrm{ODE} 5) \\
&\left(\frac{H C S_{\max }}{1+\left(H F C / H C S_{t}\right)^{H S}}\right)
\end{aligned}
$$

$$
\begin{aligned}
\frac{d[H C E]}{d t}= & k_{9}[A C A T][H F C] \\
& -k_{10}[H C E][C E H] \quad(\text { ODE 6) }
\end{aligned}
$$

These ODEs were added to the system and the model was re-parameterised by sequential adjustment of the parameters in order to bring both hepatic cholesterol esters and the hepatic pool of free cholesterol into a steady-state (Figure 6, graphs B and C).

\section{Hepatic release of very low density lipoprotein cholesterol}

According to Glomset et al. the amount of cholesterol secreted hepatically in VLDL is considered to be in the region of $800 \mathrm{mg} /$ day and could be as high as $3000 \mathrm{mg} /$ day [90]. Therefore, it was assumed that in the steady state $\approx 1000 \mathrm{mg} /$ day of cholesterol was incorporated into VLDL. The rate of incorporation of cholesterol into VLDL was assumed to be proportional to the concentration of hepatic cholesterol and this reaction was assigned the rate constant $k_{12}$.

\section{The turnover of hepatic $L D L$ receptors}

According to Dietschy, the rate of lipoprotein removal from the circulation by the liver is dependent on the concentration of the lipoprotein and hepatic LDL receptors (HLDLRs) [82]. Brown and Goldstein established that the synthesis of HLDLRs is subject to inhibition by the intracellular concentration of free cholesterol $[44,91]$. Thus represented the synthesis of HLDLRs with equation 6 , where $k_{\text {hrs }}$ is the rate constant for the synthesis of HLDLRs.

Synthesis of hepatic LDL receptors

$$
=\frac{k_{h r s}[H L D L R s]}{[H F C]}
$$


It is challenging to determine the actual number of HLDLRs present on a human organ such as the liver. Although, the number has been estimated at a cellular level, it was not feasible to try and determine it for a whole-body model of cholesterol metabolism. Thus, an arbitrary value of 100 was assigned to represent a fully active complement of HLDLRs and the rate constant $k_{13}$ was assigned to represent the rate of HLDLRs degradation. Thus, ODE 7 was derived to describe the turnover of HLDLRs. It is important to note that this type of approach has been used previously to model this process, whereby the regulation of receptor synthesis is handled via reciprocal feedback due to cholesterol concentration [92].

$$
\begin{aligned}
\frac{d[H L D L R s]}{d t}= & \frac{k_{h r s}[H L D L R s]}{[H F C]} \\
& -k_{13}[H L D L R s]
\end{aligned}
$$

It is known that a certain amount of VLDL-C is removed via $H L D L R s$ [82]. It was difficult to obtain quantitative data about this process; however the literature indicated that this is not the major route by which cholesterol re-enters the liver. It was therefore assumed that only a negligible amount of VLDL-C is taken up via this avenue $(\approx 100 \mathrm{mg} /$ day $)$ and was assigned the rate constant $k_{14}$.

\section{Hepatic $L D L$ receptor mediated removal of VLDL-C from the plasma}

The enzyme LPL acts on VLDLs to reduce them to IDLs [93]. It was assumed that this process is dependent on the concentration of LPL and of VLDL-C and was assigned the rate constant $k_{15}$. Thus, ODE 8 was derived to represent the change with time of VLDL-C.

$$
\begin{aligned}
\frac{d[V L D L C]}{d t}= & k_{12}[H F C]-k_{14}[H L D L R s][V L D L C] \\
& -k_{15}[\mathrm{LPL}][\mathrm{VLDLC}] \quad(\mathrm{ODE} 8)
\end{aligned}
$$

Similar to VLDL-C, a certain amount of IDL-C reenters the liver via HLDLRs and the assumption was made that this is $\approx 10 \%$ of the overall particle composition. IDLs are further catabolised to LDLs by the enzyme hormone sensitive lipase (HSL). The majority of LDL-C $(\approx 75 \%)$ is taken up by the liver, while the remainder is removed by peripheral tissue. Based on the literature it was assumed that receptor independent uptake of LDL-C is of minor importance and accounts for only $50 \mathrm{mg} /$ day of LDL-C removed from the tissue [9496]. This value was split equally between the liver and peripheral tissue. Based on this information ODEs 9 and 10 were derived to describe the change in IDL-C and LDL-C with time. $k_{16}$ is the rate constant for removal of IDLC via the hepatic receptor and $k_{17}$ is the rate constant for the formation of LDL-C, while $k_{18}$ is the rate constant for HLDLR uptake of LDL-C and $k_{19}$ is the rate constant for the hepatic receptor independent uptake of LDL-C. Peripheral LDL receptor (PLDLRs) and non-peripheral receptor uptake are represented by the rate constants $k_{20}$ and $k_{21}$, respectively.

$$
\begin{aligned}
\frac{d[I D L C]}{d t}= & k_{15}[L P L][V L D L C]-k_{16}[H L D L R][I D L C] \\
& -k_{17}[H S L][I D L C] \quad(\mathrm{ODE} 9) \\
\frac{d[L D L C]}{d t}= & k_{17}[H S L][I D L C]-k_{18}[L D L C][H L D L R s] \\
& -k_{19}[L D L C]-k_{20}[L D L C][P L D L R s] \\
& -k_{21}(\mathrm{ODE} 10)
\end{aligned}
$$

Parameterisation to establish the steady states of $L D L-C$, IDL-C VLDL-C

As the system had now increased in size significantly, further simulations were completed to establish the steady-state levels of the various species. Again the model was re-parameterized using the data outlined and the system numerically solved with MathSBML. After adjustment of the parameters LDL-C, IDL-C and VLDL$\mathrm{C}$ entered steady states based on known literature values (Figures 6, graphs D and E). It is important to note that the values of both the peripheral pool of free cholesterol (PFC) and PLDLRs were held at fixed arbitrary values of 100 to facilitate this process.

\section{Further additions to the peripheral compartment}

Once the first three compartments demonstrated reliable biological outputs, the final phase of model building involved the addition of the peripheral compartment. Table 7 outlines how the amount of cholesterol in the peripheral tissue was calculated based on previous calculations for the amount of cholesterol in the liver and intestine. Previously, the rate of peripheral cholesterol synthesis was estimated to be $441 \mathrm{mg} /$ day. This was completed in exactly the same manner as for the hepatic pool, where the rate constants $k_{\text {prs }}$ represents the synthesis of PLDLRs, $k_{22}$ represents the degradation of PLDLRs, $k_{23}$ represents the formation of peripheral cholesterol esters (PCE) and $k_{24}$ is the release of stored peripheral cholesterol. Additionally, according to Myant, a certain amount of cholesterol can be converted to steroid hormones. For example, a normal 
Table 7 Calculation of cholesterol in the peripheral tissue

\begin{tabular}{ll}
\hline Tissue & Concentration \\
\hline Liver & $70000 \mathrm{mg}$ \\
\hline Intestine & $3120 \mathrm{mg}$ \\
\hline $\begin{array}{l}\text { Remaining cholesterol in } \\
\text { peripheral tissue }\end{array}$ & $70000-3120=66880 \mathrm{mg}$ \\
\hline Liver & $\begin{array}{l}10000 \mathrm{mg} \text { of stored } \\
\text { cholesterol, which represents } \\
14 \% \text { of overall hepatic cholesterol }\end{array}$ \\
\hline Peripheral tissue & $\begin{array}{l}\text { Assuming } 14 \% \text { is stored here: } \\
14 \% \text { of } 66880=3963.2 \mathrm{mg}\end{array}$ \\
\hline $\begin{array}{l}\text { Peripheral free } \\
\text { cholesterol }\end{array}$ & $66880-9363.2=57516.8 \mathrm{mg}$ \\
\hline
\end{tabular}

man may excrete 25-50 mg/day of total adrenocortical and gonadal hormones [62]. As this loss has to be replaced, this was included in the model by the addition of the rate constant $k_{25}$ which represents steroid hormone synthesis (PSS), which was in essence a sink species. ODEs 11 and 12 were then derived. Again at this point the model was re-parameterised and steady-states produced.

$$
\begin{aligned}
\frac{d[P C E]}{d t}= & k_{23}[A C A T][P F C] \\
& -k_{24}[P C E][C E H] \quad(\text { ODE 11) } \\
\frac{d[P F C]}{d t}= & k_{21}-k_{25}+k_{24}[P C E][C E H] \\
& -k_{23}[\text { ACAT }][P F C] \frac{P C S_{\max }}{1+\left(P F C / P F C_{t}\right)^{P C S S}} \\
& +k_{20}[L D L C][P L D L R s(\mathrm{ODE} 12)
\end{aligned}
$$

\section{Reverse cholesterol transport and the final steps to a whole-body mathematical model}

Based on current literature it was assumed that the production of HDL-C is dependent on three factors; the concentration of peripheral free cholesterol, the population of nascent HDL particles and the activity of the enzyme LCAT which has a role to play in the conversion of free peripheral cholesterol into cholesteryl esters which are then sequestered into the core of a lipoprotein particle, eventually making the newly synthesized HDL particle. The enzyme is bound to HDLs and LDLs in the blood plasma.

Firstly, the population of nascent HDLs had to be represented. Nascent HDLs are synthesised in the intestine. As extensive literature searches revealed little quantitative information related to this process, an arbitrary

value of $100 \mathrm{mg} /$ day was assigned for the synthesis of nascent HDL. This value was then split evenly between its two points of origin; the intestine and liver. ODE 13 was then derived where $k_{8}$ represents the intestinal rate of nascent HDL $(N H D L)$ synthesis and $k_{11}$ represents the hepatic synthesis of $N H D L$.

$$
\frac{d[N H D L]}{d t}=k_{8}+k_{11}
$$

Reverse cholesterol transport is important as it represents the only route for excess cholesterol generated in the peripheral tissue to be removed from the body, either by secretion into bile or by conversion into bile acids [55]. In the steady state, RCT should equal the rate of synthesis of cholesterol in the peripheral tissue [41]. Previously the synthesis of cholesterol in the peripheral tissue was calculated to equal $441 \mathrm{mg} /$ day. Therefore, $441 \mathrm{mg}$ of cholesterol that originated in peripheral tissue should enter the liver via HDL and this return of cholesterol via HDL-C to the liver may follow one of several routes. In the presence of CETP, a portion of the HDL cholesterol is transferred to either VLDL or LDL and ultimately returned to the liver via HLDLRs; therefore it was assumed that $10 \%$ of the cholesterol that is scavenged by HDL-C makes its way to the liver via this path. Alternatively, HDL-C is delivered to the liver via scavenger receptor class B1 [SRB1]. Thus based on this information the change in HDL-C with time was represented by ODE 14 , where $k_{26}$ is the rate constant for the enzymatic dependent scavenging of cholesterol from the peripheral compartment, $k_{27}$ is the rate constant for the CETP dependent transfer of cholesterol to VLDL and $k_{28}$ is the rate constant for the CETP mediated transfer of cholesterol to LDL. Finally, $k_{29}$ is the rate constant for reverse cholesterol transport.

$$
\begin{aligned}
\frac{d[H D L C]}{d t}= & k_{26}[L C A T][N H D L][P F C] \\
& -k_{27}[C E T P][H D L C] \\
& -k_{28}[\text { CETP }][H D L C] \\
& -k_{29}[H D L C][S R B 1]
\end{aligned}
$$

(ODE 14)

\section{Updating of ODEs 5 and ODE6}

ODE 5 and ODE 6 were updated to include the changes described above. Again the system was re-parameterized and brought into a steady state to reflect these new changes. HDL-C reached a steady state which was based on the literature for normolipidemic male. All reactions and parameters are summarised in Table 2. 


$$
\begin{gathered}
\frac{d[H F C]}{d t}=k_{19}+\left(k_{10}[H C E][C E H]\right)-\left(\frac{B C R_{\max }}{1+\left(B C R_{t} / H F C\right)^{B S}}\right) \\
\left(\frac{H C S_{\max }}{1+\left(H F C / H C S_{t}\right)^{H S}}\right)+\left(k_{6}[I B S][I C]\right)+\left(k_{16}[H L D L R s][I D L C]\right)+ \\
\left(k_{18}[H L D L R s][L D L C]\right)+\left(k_{29}[H D L C][S R B 1]\right)\left(k_{14}[H L D L R s][V L D L C]\right) \\
-k_{12}[H F C]-\left(\frac{k_{5}[H F C]}{[B S P]}\right)-k_{9}[A C A T][H F C] \quad(\text { Updated ODE 5) } \\
\frac{d[P F C]}{d t}=k_{21}-k_{25}+k_{24}[P C E][C E H]-k_{26}[L C A T][N H D L][P F C]-k_{23}[A C A T][P F C]+ \\
\frac{P C S_{\max }}{1+\left(P F C / P F C_{t}\right)^{P C S S}}+k_{20}[L D L C][P L D L R s \text { (Updated ODE 6) }
\end{gathered}
$$

\section{Model exchangeability, SBML and submission to the Biomodels database}

The model was coded into SBML using an export function in MathSBML (Additional file 2). Unlike computer languages such as $\mathrm{C}, \mathrm{C}++$ and Java, SBML was not designed to be coded manually; instead a number of tools are available that automatically generate SBML. The code can then be exchanged between tools supporting SBML [17]. In this case the model code was transferred into the software tool Copasi to facilitate parameter scanning [79]. Please note that when the ODEs are integrated in Copasi using the initial conditions, LDL-C enters a slightly higher steady-state than it does with MathSBML. In addition the model was submitted to the Biomodels database http:// www.ebi.ac.uk/biomodels-main/ to facilitate its updating and future exchange (MODEL1206010000).

\section{Additional files}

Additional file 1: Copasi file of Whole-Body Model of Cholesterol Metabolism.

Additional file 2: SBML file of Whole-Body Model of Cholesterol Metabolism.

\section{Competing interests}

The authors declared that they have no competing interests.

\section{Authors' contributions}

MTM ${ }^{\mathrm{C}} \mathrm{A}$ was responsible for the computational mathematical modeling and sensitivity analysis of the system. MTM'A was also responsible for data mining and acquisition of variable and parameter data. TBLK provided insight into the effects of ageing on the system, while DJW and JLJ advised on the modeling of the system. All authors read and approved the final manuscript.

\section{Acknowledgements}

We acknowledge Fotios Drenos, Daryl Shanley and Carole Proctor for their advice throughout the duration of this work. We also acknowledge Chris Packard for his advice on cholesterol metabolism. MT Mc Auley was funded by an EPSRC CASE studentship with Unilever PLC. The research was also supported by the National Institute for Health Research (NIHR) Newcastle Biomedical Research Centre based at Newcastle upon Tyne Hospitals NHS Foundation Trust and Newcastle University.

\section{Author details}

${ }^{1}$ Campus for Ageing and Vitality, Newcastle University, Henry Wellcome Biogerontology Building, Newcastle upon Tyne NE4 5PL, United Kingdom. ${ }^{2}$ School of Mathematics \& Statistics, Newcastle University, Newcastle upon Tyne NE1 7RU, UK. ${ }^{3}$ Unilever R\&D, Port Sunlight, Quarry Road East, Bebington, Wirral CH63 3JW, UK.

Received: 28 February 2012 Accepted: 21 September 2012 Published: 10 October 2012

\section{References}

1. Barzilai N, Atzmon G, Derby CA, Bauman JM, Lipton RB: A genotype of exceptional longevity is associated with preservation of cognitive function. Neurology 2006, 67(12):2170-2175.

2. Barzilai N, Atzmon G, Schechter C, Schaefer EJ, Cupples AL, Lipton R, Cheng S, Shuldiner AR: Unique lipoprotein phenotype and genotype associated with exceptional longevity. JAMA 2003, 290(15):2030-2040.

3. Capewell S, Allender S, Critchley J, Lloyd-Williams F, O'Flaherty M, Rayner M, Scarborough P: Cardio \& Vascular Coalition Modelling the UK burden of Cardiovascular Disease to 2020:A Research Report for the Cardio \& Vascular Coalition and the British Heart Foundation. In British Heart Foundation. 2008.

4. Castelli WP, Garrison RJ, Wilson PW, Abbott RD, Kalousdian S, Kannel WB: Incidence of coronary heart disease and lipoprotein cholesterol levels. The Framingham Study. JAMA 1986, 256(20):2835-2838.

5. Berliner J, Leitinger N, Watson A, Huber J, Fogelman A, Navab M: Oxidized lipids in atherogenesis: formation, destruction and action. Thromb Haemost 1997, 78(1):195-199.

6. Heiss G, Tamir I, Davis CE, Tyroler HA, Rifkand BM, Schonfeld G, Jacobs D, Frantz ID Jr: Lipoprotein-cholesterol distributions in selected North American populations: the lipid research clinics program prevalence study. Circulation 1980, 61(2):302-315.

7. Abbott RD, Garrison RJ, Wilson PW, Epstein FH, Castelli WP, Feinleib M LaRue C: Joint distribution of lipoprotein cholesterol classes. The Framingham study. Arteriosclerosis 1983, 3(3):260-272.

8. Hollander D, Morgan D: Increase in cholesterol intestinal absorption with aging in the rat. Exp Gerontol 1979, 14(4):201-204.

9. Wang DQ: Aging per se is an independent risk factor for cholesterol gallstone formation in gallstone susceptible mice. J Lipid Res 2002 43(11):1950-1959.

10. Grundy SM, Vega GL, Bilheimer DW: Kinetic mechanisms determining variability in low density lipoprotein levels and rise with age. Arteriosclerosis 1985, 5(6):623-630.

11. Hood L: Systems biology: integrating technology, biology, and computation. Mech Ageing Dev 2003, 124(1):9-16.

12. Wang K, Lee I, Carlson G, Hood L, Galas D: Systems biology and the discovery of diagnostic biomarkers. Dis Markers 2010, 28(4):199-207.

13. Kirkwood TBL, Boys RJ, Gillespie CS, Proctor CJ, Shanley DP, Wilkinson DJ: (2005) Computer Modeling in the Study of Aging, in S. N. Austad, E. J. Masoro (eds.): Computer Modeling in the Study of Aging. In Handbook of the Biology of Aging. Academic.; 2005:334-357. 
14. Homan R, Krause BR: Established and emerging strategies for inhibition of cholesterol absorption. Curr PharmDes 1997, 3:29-44.

15. Goodman DS, Smith FR, Seplowitz AH, Ramakrishnan R, Dell RB: Prediction of the parameters of whole body cholesterol metabolism in humans. J Lipid Res 1980, 21(6):699-713.

16. Kervizic $G$, Corcos L: Dynamical modeling of the cholesterol regulatory pathway with Boolean networks. BMC Syst Biol 2008, 2:99.

17. Hucka M, Finney A, Sauro HM, Bolouri H, Doyle JC, Kitano H, Arkin AP, Bornstein BJ, Bray D, Cornish-Bowden A, et al: The systems biology markup language (SBML): a medium for representation and exchange of biochemical network models. Bioinformatics 2003, 19(4):524-531.

18. Li C, Donizelli M, Rodriguez N, Dharuri H, Endler L, Chelliah V, Li L, He E, Henry A, Stefan Ml, et al: BioModels Database: An enhanced, curated and annotated resource for published quantitative kinetic models. BMC Syst Biol 2010, 4:92

19. Havel RJ: Biology of cholesterol, lipoproteins and atherosclerosis. Clin Exp Hypertens A 1989, 11(5-6):887-900.

20. Brown AJ: Atherosclerosis: cell biology and lipoproteins: cholesterol absorption inhibitors: gateway therapy for hypercholesterolaemia. Curr Opin Lipidol 2002, 13(6):701-703.

21. Bosner MS, Lange LG, Stenson WF, Ostlund RE Jr: Percent cholesterol absorption in normal women and men quantified with dual stable isotopic tracers and negative ion mass spectrometry. J Lipid Res 1999, 40(2):302-308

22. Hui DY, Howles PN: Molecular mechanisms of cholesterol absorption and transport in the intestine. Semin Cell Dev Biol 2005, 16(2):183-192

23. Hernell O, Staggers JE, Carey MC: Physical-chemical behavior of dietary and biliary lipids during intestinal digestion and absorption. 2. Phase analysis and aggregation states of luminal lipids during duodenal fat digestion in healthy adult human beings. Biochemistry 1990, 29(8):2041-2056.

24. Westergaard H, Dietschy JM: The mechanism whereby bile acid micelles increase the rate of fatty acid and cholesterol uptake into the intestinal mucosal cell. J Clin Invest 1976, 58(1):97-108.

25. Chijiiwa K, Linscheer WG: Distribution and monomer activity of cholesterol in micellar bile salt: effect of cholesterol level. Am J Physio 1987, 252(3 Pt 1):G309-G314.

26. Hauser H, Dyer JH, Nandy A, Vega MA, Werder M, Bieliauskaite E, Weber FE, Compassi S, Gemperli A, Boffelli D, et al: Identification of a receptor mediating absorption of dietary cholesterol in the intestine. Biochemistry 1998, 37(51):17843-17850.

27. Detmers PA, Patel S, Hernandez M, Montenegro J, Lisnock JM, Pikounis B, Steiner M, Kim D, Sparrow C, Chao YS, et al: A target for cholestero absorption inhibitors in the enterocyte brush border membrane. Biochim Biophys Acta 2000, 1486(2-3):243-252

28. Voshol PJ, Schwarz M, Rigotti A, Krieger M, Groen AK, Kuipers F: Down-regulation of intestinal scavenger receptor class B, type I (SR-BI) expression in rodents under conditions of deficient bile delivery to the intestine. Biochem J 2001, 356(Pt 2):317-325.

29. Mahley RW, Innerarity TL: Lipoprotein receptors and cholesterol homeostasis. Biochim Biophys Acta 1983, 737(2):197-222

30. Havel RJ: Postprandial lipid metabolism: an overview. Proc Nutr Soc 1997 56(2):659-666.

31. Spady DK, Turley SD, Dietschy JM: Rates of low density lipoprotein uptake and cholesterol synthesis are regulated independently in the liver. J Lipid Res 1985, 26(4):465-472.

32. St-Pierre MV, Kullak-Ublick GA, Hagenbuch B, Meier PJ: Transport of bile acids in hepatic and non-hepatic tissues. J Exp Bio/ 2001, 204(Pt 10):1673-1686.

33. Hofmann AF: Bile Acids: The Good, the Bad, and the Ugly. News Physiol Sci 1999, 14:24-29.

34. Olivecrona G, Olivecrona T: Triglyceride lipases and atherosclerosis. Curr Opin Lipidol 1995, 6(5):291-305.

35. Packard CJ, Shepherd J: Lipoprotein heterogeneity and apolipoprotein B metabolism. Arterioscler Thromb Vasc Biol 1997, 17(12):3542-3556.

36. Hussain MM, Strickland DK, Bakillah A: The mammalian low-density lipoprotein receptor family. Annu Rev Nutr 1999, 19:141-172.

37. Willnow TE, Nykjaer A, Herz J: Lipoprotein receptors: new roles for ancient proteins. Nat Cell Biol 1999, 1(6):E157-E162.

38. Brown MS, Goldstein JL: Sterol regulatory element binding proteins (SREBPs): controllers of lipid synthesis and cellular uptake. Nutr Rev 1998, 56(2 Pt 2):S1-S3. discussion S54-75.
39. Small DM: Mechanisms of reversed cholesterol transport. Agents Actions Supp/ 1988, 26:135-146.

40. Fielding CJ, Fielding PE: Molecular physiology of reverse cholesterol transport. J Lipid Res 1995, 36(2):211-228.

41. Groen AK, Oude Elferink RP, Verkade HJ, Kuipers F: The ins and outs of reverse cholesterol transport. Ann Med 2004, 36(2):135-145.

42. Johnson WJ, Mahlberg FH, Rothblat GH, Phillips MC: Cholesterol transport between cells and high-density lipoproteins. Biochim Biophys Acta 1991, 1085(3):273-298.

43. Lewis GF, Rader DJ: New insights into the regulation of HDL metabolism and reverse cholesterol transport. Circ Res 2005, 96(12):1221-1232.

44. Brown MS, Goldstein JL: A receptor-mediated pathway for cholesterol homeostasis. Science 1986, 232(4746):34-47.

45. Brown MS, Goldstein JL: A proteolytic pathway that controls the cholesterol content of membranes, cells, and blood. Proc Natl Acad Sc U S A 1999, 96(20):11041-11048.

46. Miettinen TA, Gylling $\mathrm{H}$ : Synthesis and absorption markers of cholesterol in serum and lipoproteins during a large dose of statin treatment. Eur $J$ Clin Invest 2003, 33(11):976-982.

47. Watts GF, Chan DC, Barrett PH, O'Neill FH, Thompson GR: Effect of a statin on hepatic apolipoprotein B-100 secretion and plasma campesterol levels in the metabolic syndrome. Int J Obes Relat Metab Disord 2003, 27(7):862-865

48. Grundy SM, Vega GL, Bilheimer DW: Influence of combined therapy with mevinolin and interruption of bile-acid reabsorption on low density lipoproteins in heterozygous familial hypercholesterolemia. Ann Intern Med 1985, 103(3):339-343.

49. Ericsson S, Eriksson M, Vitols S, Einarsson K, Berglund L, Angelin B: Influence of age on the metabolism of plasma low density lipoproteins in healthy males. J Clin Invest 1991, 87(2):591-596.

50. Millar JS, Lichtenstein AH, Cuchel M, Dolnikowski GG, Hachey DL, Cohn JS, Schaefer EJ: Impact of age on the metabolism of VLDL, IDL, and LDL apolipoprotein B-100 in men. J Lipid Res 1995, 36(6):1155-1167.

51. Uchida K, Chikai T, Takase H, Nomura Y, Seo S, Nakao H, Takeuchi N: Age-related changes of bile acid metabolism in rats. Arch Gerontol Geriatr 1990, 10(1):37-48.

52. McNamara DJ: The impact of egg limitations on coronary heart disease risk: do the numbers add up? J Am Coll Nutr 2000, 19(5 Suppl):540S-548S

53. Knoblauch H, Schuster H, Luft FC, Reich J: A pathway model of lipid metabolism to predict the effect of genetic variability on lipid levels. J Mol Med (Berl) 2000, 78(9):507-515.

54. Chun PW, Espinosa AJ, Lee CW, Shireman RB, Brumbaugh EE: Low density lipoprotein receptor regulation. Kinetic models. Biophys Chem 1985, 21(3-4):185-209.

55. Wattis JA, O'Malley B, Blackburn H, Pickersgill L, Panovska J, Byrne HM, Jackson KG: Mathematical model for low density lipoprotein (LDL) endocytosis by hepatocytes. Bull Math Biol 2008, 70(8):2303-2333.

56. Adiels M, Packard C, Caslake MJ, Stewart P, Soro A, Westerbacka J, Wennberg B, Olofsson SO, Taskinen MR, Boren J: A new combined multicompartmental model for apolipoprotein B-100 and triglyceride metabolism in VLDL subfractions. J Lipid Res 2005, 46(1):58-67.

57. Erkkila AT, Lichtenstein AH: Fiber and cardiovascular disease risk: how strong is the evidence? J Cardiovasc Nurs 2006, 21(1):3-8.

58. Brown L, Rosner B, Willett WW, Sacks FM: Cholesterol-lowering effects of dietary fiber: a meta-analysis. Am J Clin Nutr 1999, 69(1):30-42.

59. Lees AM, Mok HY, Lees RS, McCluskey MA, Grundy SM: Plant sterols as cholesterol-lowering agents: clinical trials in patients with hypercholesterolemia and studies of sterol balance. Atherosclerosis 1977 28(3):325-338

60. Mattson FH, Volpenhein RA, Erickson BA: Effect of plant sterol esters on the absorption of dietary cholesterol. J Nutr 1977, 107(7):1139-1146.

61. Law M: Plant sterol and stanol margarines and health. BMJ 2000 320(7238):861-864

62. Katan MB, Grundy SM, Jones P, Law M, Miettinen T, Paoletti R: Efficacy and safety of plant stanols and sterols in the management of blood cholesterol levels. Mayo Clin Proc 2003, 78(8):965-978.

63. St-Onge MP, Jones PJ: Phytosterols and human lipid metabolism: efficacy, safety, and novel foods. Lipids 2003, 38(4):367-375.

64. Scheer M, Grote A, Chang A, Schomburg I, Munaretto C, Rother M, Sohngen C, Stelzer M, Thiele J, Schomburg D: BRENDA, the enzyme information system in 2011. Nucleic Acids Res 2011, 39(Database issue):D670-D676. 
65. Cobbold CA, Sherratt JA, Maxwell SR: Lipoprotein oxidation and its significance for atherosclerosis: a mathematical approach. Bull Math Biol 2002, 64(1):65-95.

66. Krause F, Uhlendorf J, Lubitz T, Schulz M, Klipp E, Liebermeister W: Annotation and merging of SBML models with semanticSBML. Bioinformatics 2010, 26(3):421-422.

67. Schulz M, Uhlendorf J, Klipp E, Liebermeister W: SBMLmerge, a system for combining biochemical network models. Genome Inform 2006, 17(1):62-71.

68. Witztum JL, Steinberg D: Role of oxidized low density lipoprotein in atherogenesis. J Clin Invest 1991, 88(6):1785-1792.

69. Steinberg D: Low density lipoprotein oxidation and its pathobiological significance. J Biol Chem 1997, 272(34):20963-20966.

70. Heijmans BT, Beekman M, Houwing-Duistermaat JJ, Cobain MR, Powell J Blauw GJ, van der Ouderaa F, Westendorp RG, Slagboom PE: Lipoprotein particle profiles mark familial and sporadic human longevity. PLOS Med 2006, 3(12):e495.

71. Rahilly-Tierney CR, Spiro A 3rd, Vokonas P, Gaziano JM: Relation between highdensity lipoprotein cholesterol and survival to age 85 years in men (from the VA normative aging study). Am J Cardiol 2011, 107(8):1173-1177.

72. Goldstein B, Wofsy C, Bell G: Interactions of low density lipoprotein receptors with coated pits on human fibroblasts: estimate of the forward rate constant and comparison with the diffusion limit. Proc Nat/ Acad Sci U S A 1981, 78(9):5695-5698.

73. Keizer J, Ramirez J, Peacock-Lopez E: The effect of diffusion on the binding of membrane-bound receptors to coated pits. Biophys J 1985, 47(1):79-87.

74. Gao H, Shi W, Freund LB: Mechanics of receptor-mediated endocytosis. Proc Natl Acad Sci U S A 2005, 102(27):9469-9474.

75. Pont F, Duvillard L, Verges B, Gambert P: Development of compartmental models in stable-isotope experiments: application to lipid metabolism. Arterioscler Thromb Vasc Biol 1998, 18(6):853-860.

76. Le Novere N, Hucka M, Mi H, Moodie S, Schreiber F, Sorokin A, Demir E, Wegner K, Aladjem MI, Wimalaratne SM, et al: The systems biology graphical notation. Nat Biotechnol 2009, 27(8):735-741.

77. Shapiro BE, Hucka M, Finney A, Doyle J: MathSBML: a package for manipulating SBML-based biological models. Bioinformatics 2004, 20(16):2829-2831.

78. Wolfram Research I: Mathematica Edition: Version 5.2. Champaign, Illinois: Wolfram Research Inc; 2005.

79. Mendes P, Hoops S, Sahle S, Gauges R, Dada J, Kummer U: Computational modeling of biochemical networks using COPASI. Methods Mol Biol 2009, 500:17-59.

80. Henderson LG, Gregory J, Irving K, Swan G: National diet and Nutrtion Survey (NDNS) of adults aged 19 to 64. 2nd edition.; 2003:70.

81. Dietschy JM, Turley SD, Spady DK: Role of liver in the maintenance of cholesterol and low density lipoprotein homeostasis in different animal species, including humans. J Lipid Res 1993, 34(10):1637-1659.

82. Dietschy JM: Theoretical considerations of what regulates low-density lipoprotein and high-density-lipoprotein cholesterol. Am J Clin Nutr 1997, 65(5 Suppl):1581S-1589S.

83. Grundy SM, Metzger AL: A physiological method for estimation of hepatic secretion of biliary lipids in man. Gastroenterology 1972, 62(6):1200-1217.

84. Soars MG, Burchell B, Riley RJ: In vitro analysis of human drug glucuronidation and prediction of in vivo metabolic clearance. $J$ Pharmacol Exp Ther 2002, 301(1):382-390.

85. Redinger RN: The coming of age of our understanding of the enterohepatic circulation of bile salts. Am J Surg 2003, 185(2):168-172.

86. Sudhop T, Lutjohann D, Kodal A, Igel M, Tribble DL, Shah S, Perevozskaya I, von Bergmann K: Inhibition of intestinal cholesterol absorption by ezetimibe in humans. Circulation 2002, 106(15):1943-1948

87. Sahlin S, Granstrom L, Gustafsson U, Stahlberg D, Backman L, Einarsson K Hepatic esterification rate of cholesterol and biliary lipids in human obesity. J Lipid Res 1994, 35(3):484-490.

88. Cook R: Distribution of sterols in organisms and in tissues. Chemistry, biochemistry, and pathology. New York: Academic Press Inc; 1958.

89. Erickson SK, Bosterling B: Cholesterol 7 alpha-hydroxylase from human liver: partial purification and reconstruction into defined phospholipidcholesterol vesicles. J Lipid Res 1981, 22(5):872-876.

90. Glomset JA, Norum KR: The metabolic role of lecithin: cholesterol acyltransferase: perspectives form pathology. Adv Lipid Res 1973, 11:1-65.
91. Brown MS, Goldstein JL: Receptor-mediated control of cholesterol metabolism. Science 1976, 191(4223):150-154.

92. August $\mathrm{E}$, Parker KH, Barahona M: A dynamical model of lipoprotein metabolism. Bull Math Biol 2007, 69(4):1233-1254.

93. Yamada N, Shames DM, Stoudemire JB, Havel RJ: Metabolism of lipoproteins containing apolipoprotein B-100 in blood plasma of rabbits: heterogeneity related to the presence of apolipoprotein E. Proc Natl Acad Sci U S A 1986, 83(10):3479-3483.

94. Spady DK, Bilheimer DW, Dietschy JM: Rates of receptor-dependent and -independent low density lipoprotein uptake in the hamster. Proc Natl Acad Sci U S A 1983, 80(11):3499-3503.

95. Spady DK, Meddings JB, Dietschy JM: Kinetic constants for receptordependent and receptor-independent low density lipoprotein transport in the tissues of the rat and hamster. J Clin Invest 1986, 77(5):1474-1481.

96. Spady DK, Huettinger M, Bilheimer DW, Dietschy JM: Role of receptorindependent low density lipoprotein transport in the maintenance of tissue cholesterol balance in the normal and WHHL rabbit. J Lipid Res 1987, 28(1):32-41.

doi:10.1186/1752-0509-6-130

Cite this article as: Mc Auley et al:: A whole-body mathematical model of cholesterol metabolism and its age-associated dysregulation. BMC Systems Biology 2012 6:130

\section{Submit your next manuscript to BioMed Central and take full advantage of:}

- Convenient online submission

- Thorough peer review

- No space constraints or color figure charges

- Immediate publication on acceptance

- Inclusion in PubMed, CAS, Scopus and Google Scholar

- Research which is freely available for redistribution 